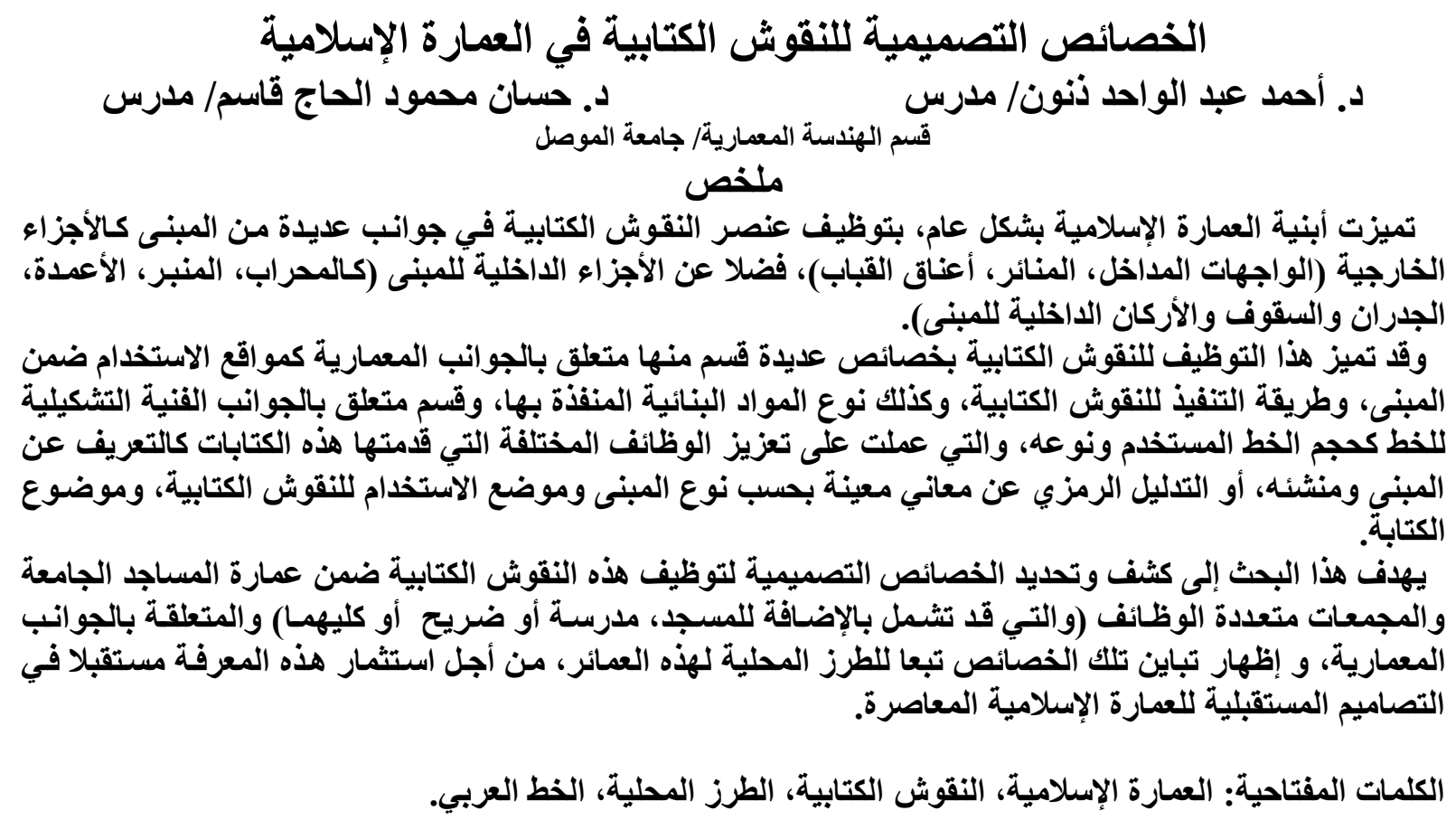

\title{
Design Characteristics of the Written Inscriptions in Islamic
} Architecture

\section{Ahmed Abdel Wahed Thanoon D. Hassan Mahmood Haj Kasim}

Abstract

Buildings in Islamic architecture are characterized in general, in employing written inscriptions in many aspects of the building; as the external elements (facades, entrances, minarets, domes ...) as well as the internal elements of the building (mihrabs, minbars, columns, walls and ceilings of the Interior...).

Employing written inscriptions has many characteristics which can be classified into two groups: the first are related to the architectural aspects, as position within the building, method of execution, building materials, the second group are related to aspects of Fine Art for the calligraphy as type of font, size and proportion ...Both characteristics contributed to enhancing the various functions provided by this writings as defining the building, and its creator, or its symbolic significance of meaning according to building type or inscriptions' position or theme.

The research aims to detect and identify design characteristics of employing inscriptions within the architecture of the Congregational mosques and Multifunctional complexes (Which include the addition of a school or Mausoleum, or both at the mosque) which are related architectural aspects, and to show dissimilarity of those characteristics depending on the local styles within Islamic architecture, in order to come up with recommendations to help implementing this knowledge in future designs of contemporary Islamic architecture.

Keywords: Islamic architecture, written inscriptions, Arabic calligraphy. 


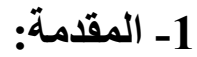

تُعد النقوش الكتابية من العناصر المهمة في الفن الإسلامي بشكل عام، وفن العمارة بشكل خاص، وفي العالم الإسلامي

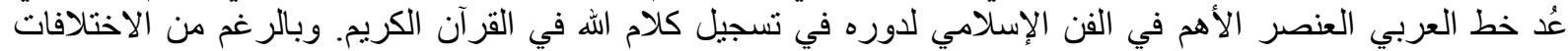

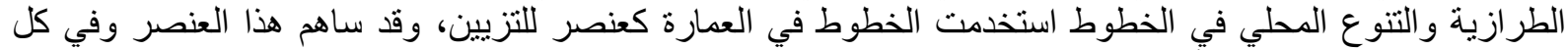

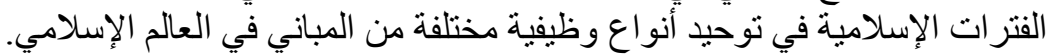

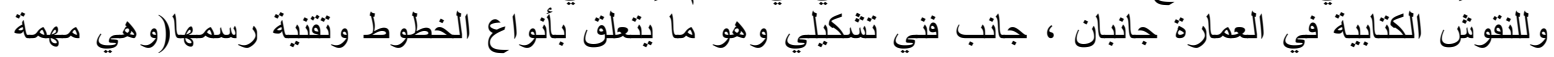

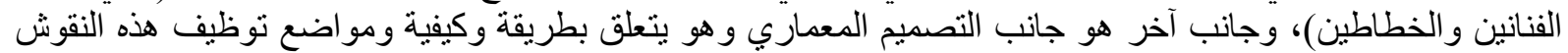

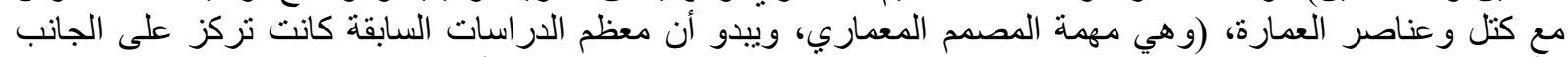

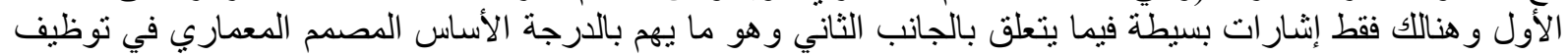
هذه النقوش الكتابية في تصاميمه المستقبلية. ولهذا يهدف هذا البحث إلى كثف وتهدئ وتحديد الخصائص التصميمية لتوظيف هذه النقوش الكتابية ضمن عمارة المساجد

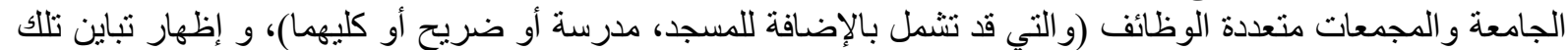

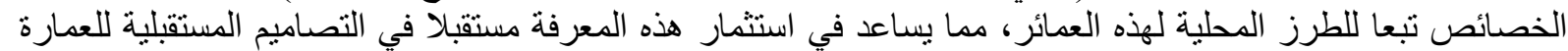

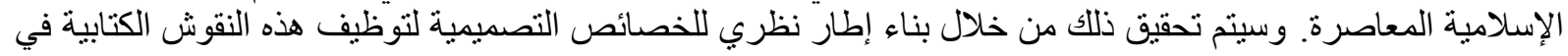

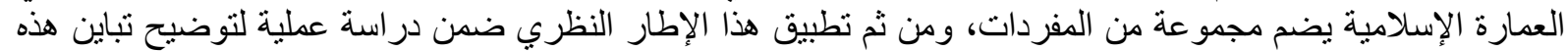

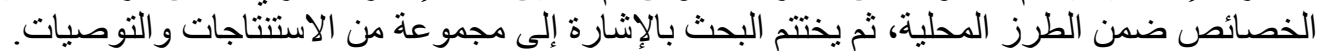

2- استعر اض الدراسات السابقة: يمكن تقسيم الدراسات السابقة إلى مجموعتين، الأولى هي دراسات التنتاول الفن الإسلامي بشكل عام مثل: (كونل،

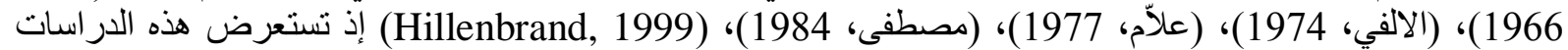

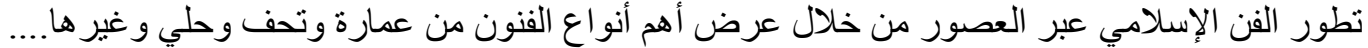

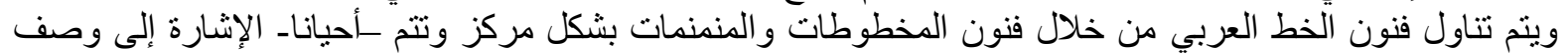

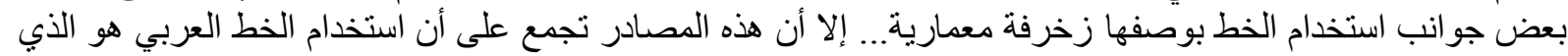

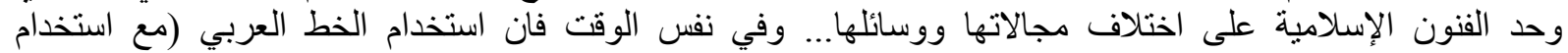

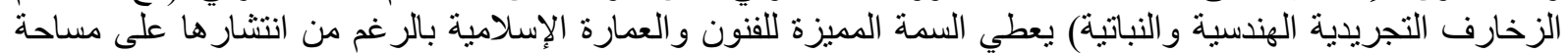

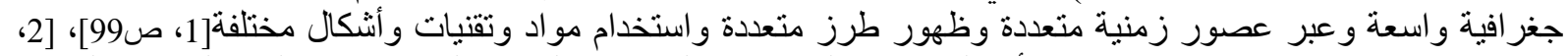

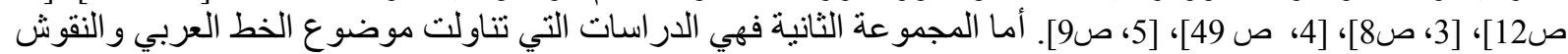
الكتابية في العمارة الإسلامية بشكل خاص، وفي هذا السياق يمكن الإشارة إلى مجمو عة الدراسات التات الآتية:

\section{1-2: دراسة الاطرقجي،" الأساسيات التصميمية للأشرطة الكتابية"، 2011:}

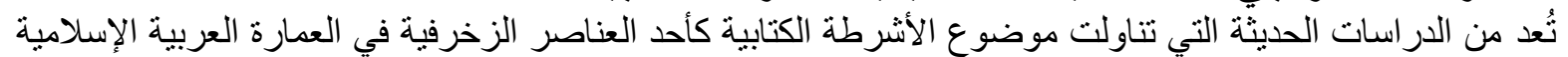

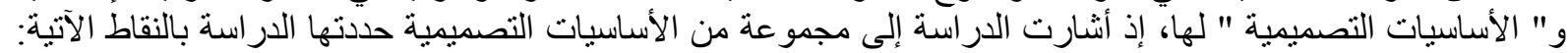

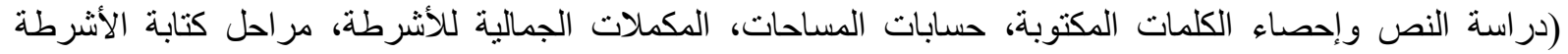

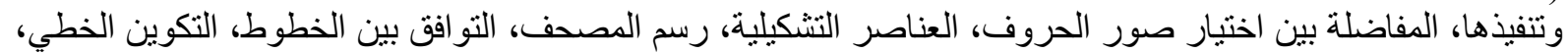

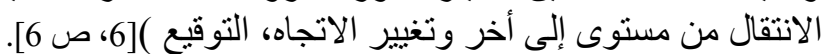

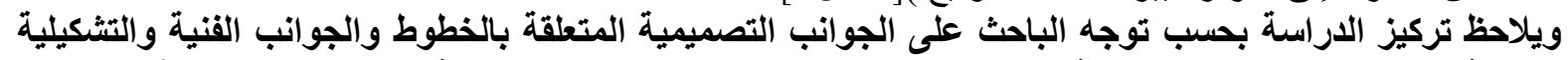

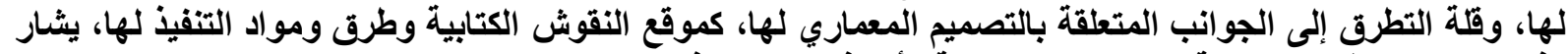

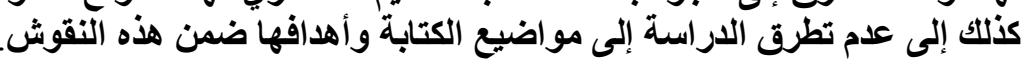

\section{2-2: دراسة القحطاني، " الخط العربي في العمارة الإسلامية "الكية 2010:}

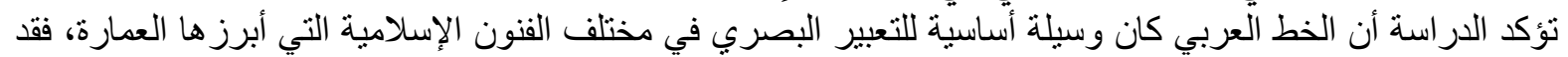

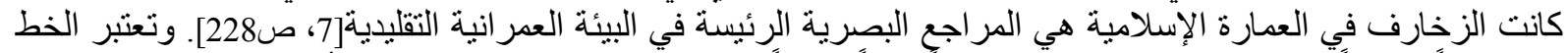

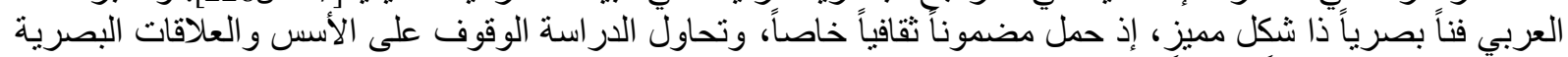

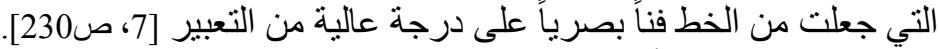
وتشير الدراسة إلى أن الخط العربي كان من بين كافة الفنون الزخرفية الفئ الفن الأقوى و الأكثر استحواذا للاهتمام بسبب:

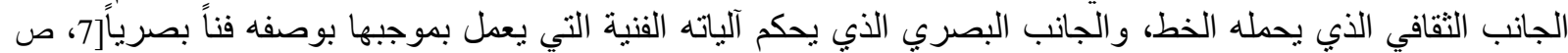


230]. كما بينت الدراسة مجموعة من المفردات المتعلقة بدراسة الموضوع كمواضيع النقوش الكتابية التي زينت مباني

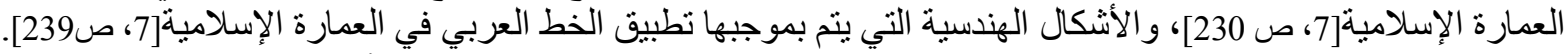

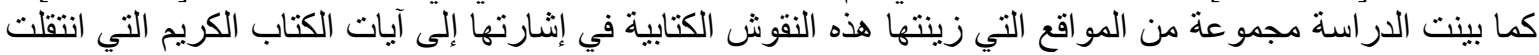

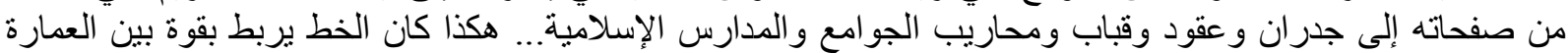

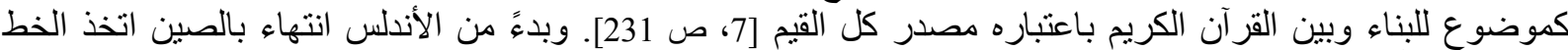

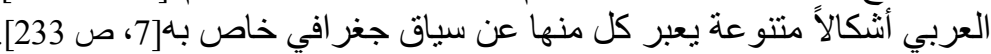

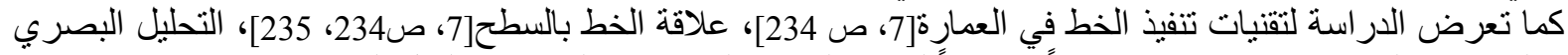

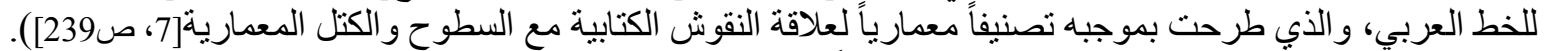

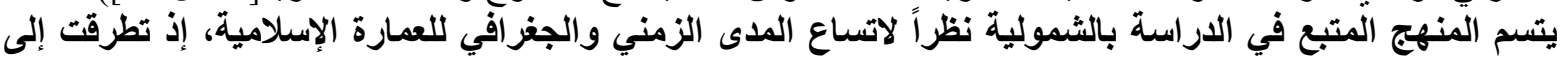

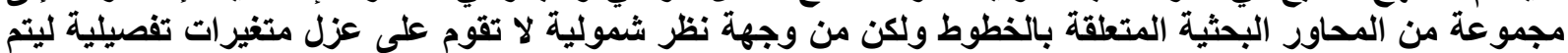

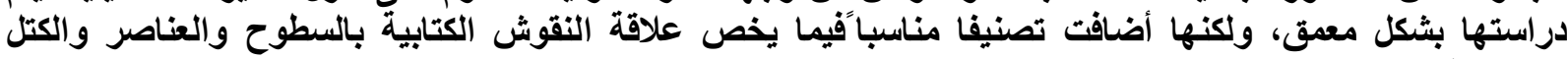
المعمارية.

\section{“"Ornament and decoration in Islamic architecture”،Clevenot 3راسة}

يشير الباحث إلى أن البعد ألزخرفي ornamental dimension للعمارة الإسلامية ومن خلال دوره الجوهري في لإسي

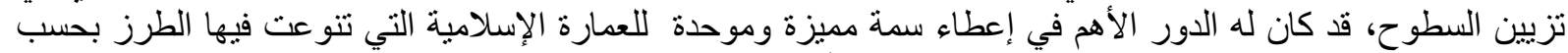

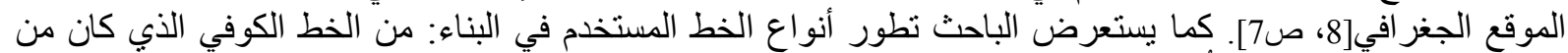

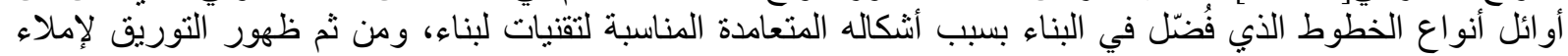

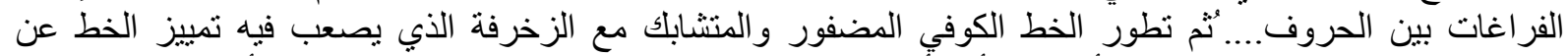

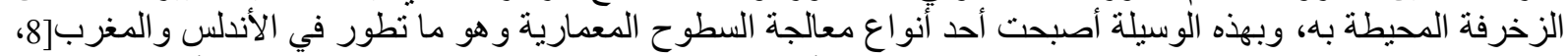

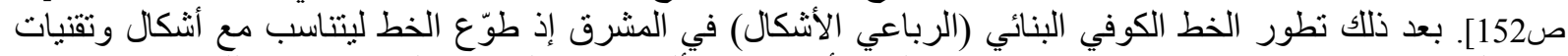

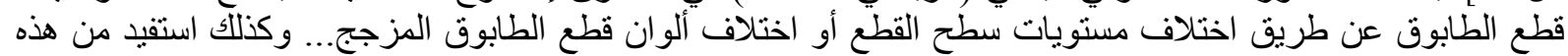

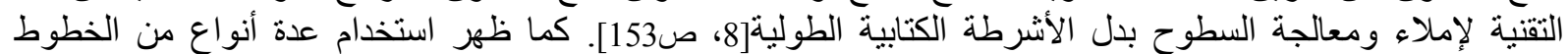

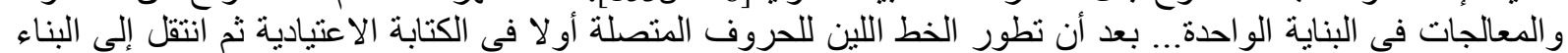

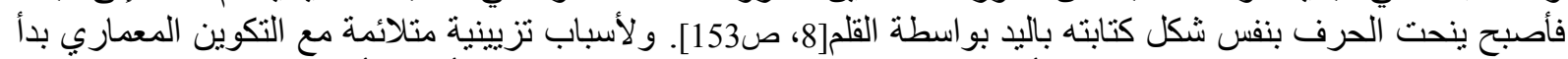

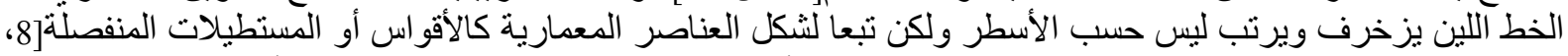

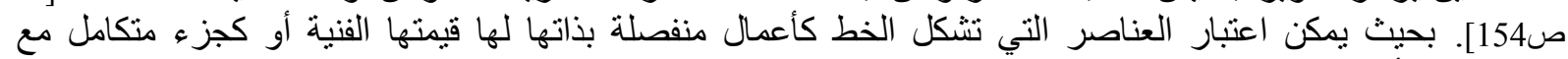

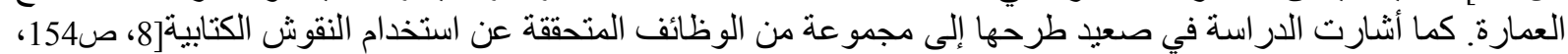

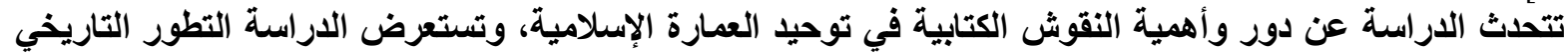

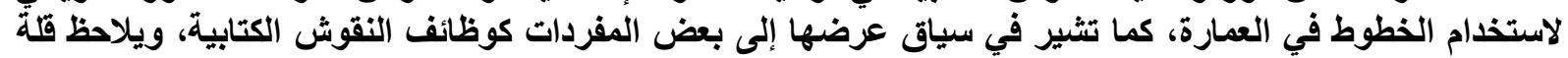

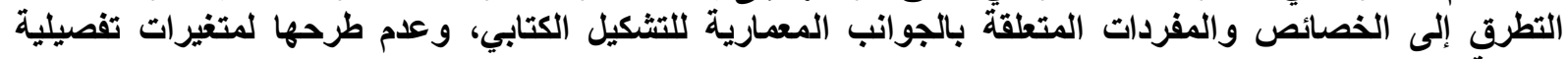

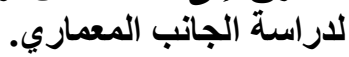

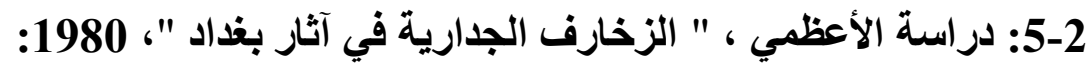

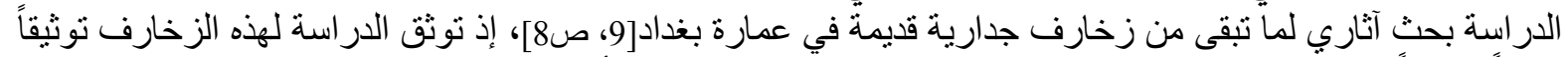

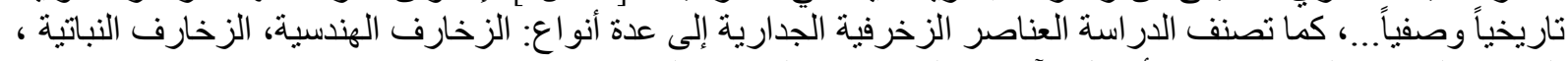

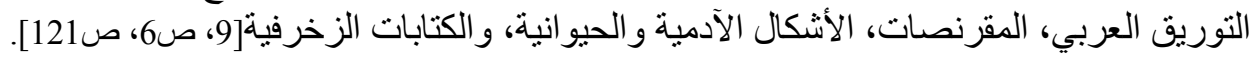

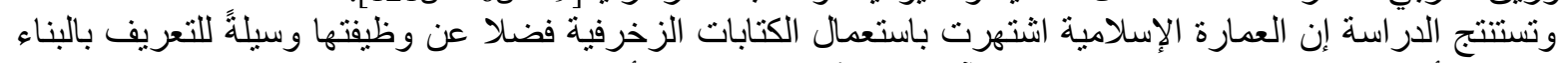

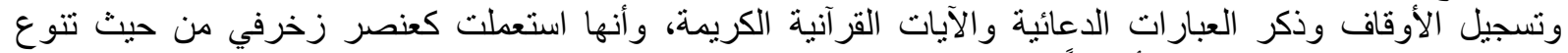

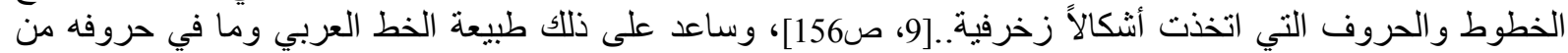

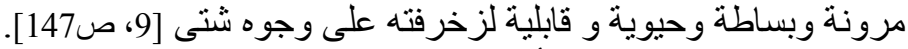

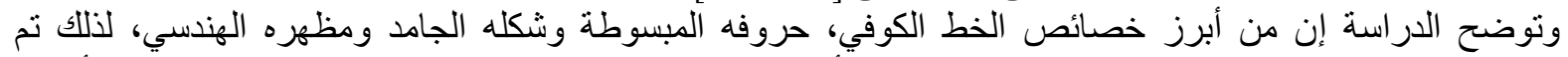

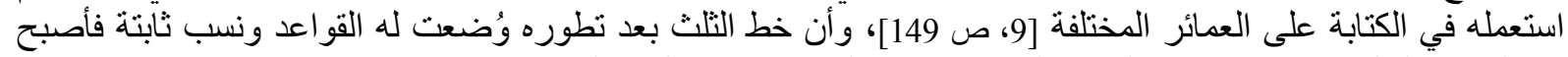

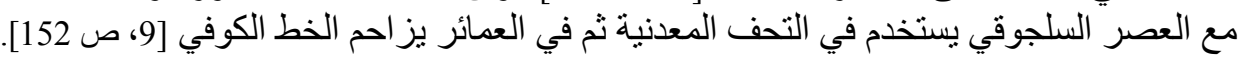


منهج الدراسة هو منهج وصفي توثيقي يتناول الزخارف الجدارية للأبنية البغدادية، والتي من ضمنها النقوش النابن الكتابية،

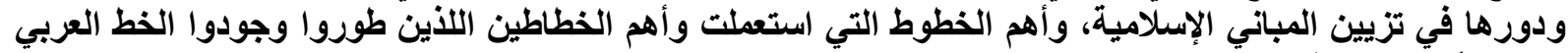

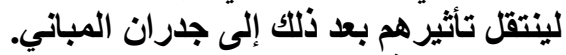

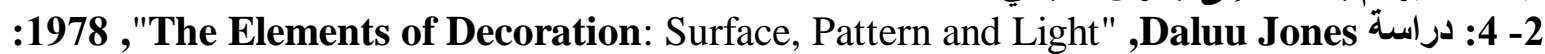

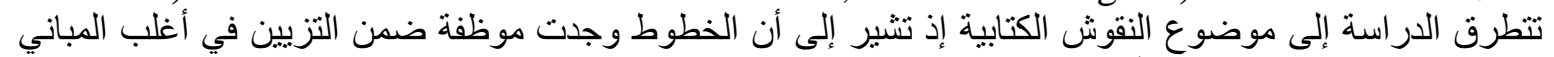

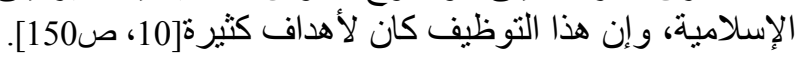

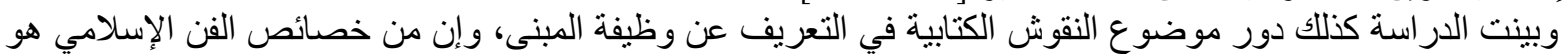

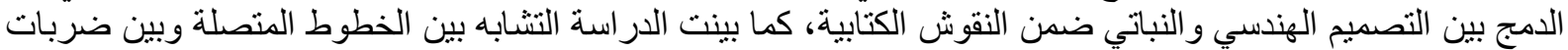

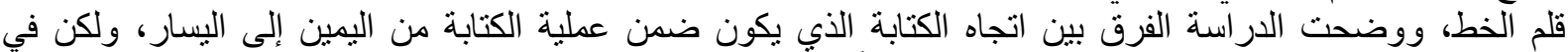

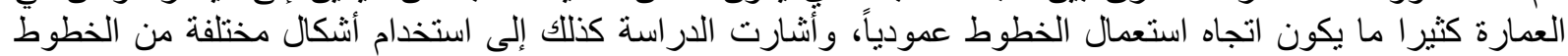

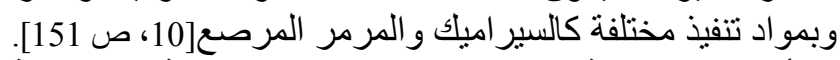

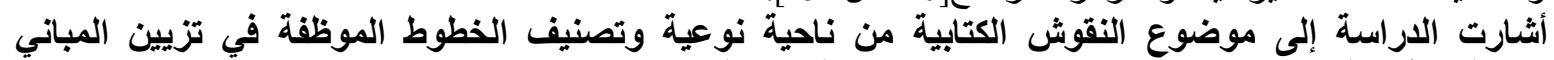

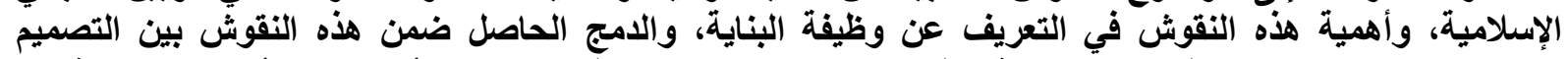

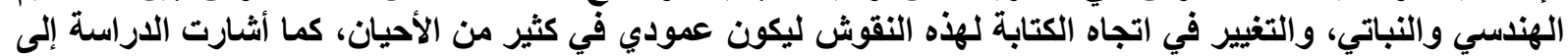
بعض مواد التفيذّ المختلفة للنقوش الكتابية.

3- مناقشة الار اسـات السابقة وتحديا مشكلة البحث، وأهدافه:

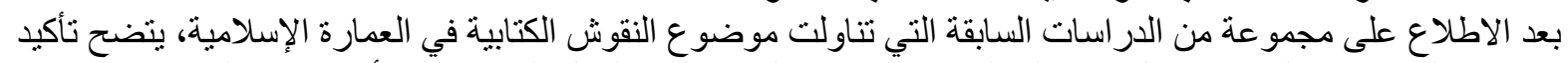

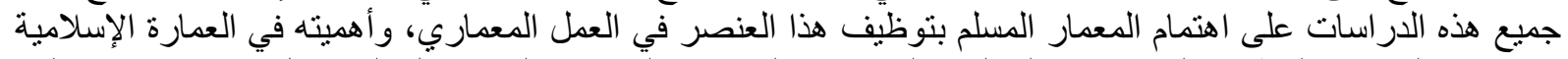

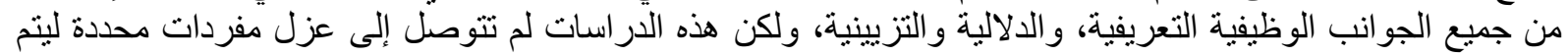

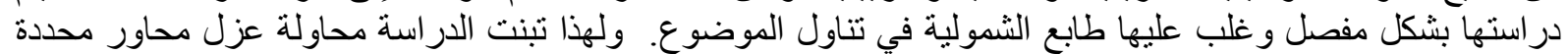

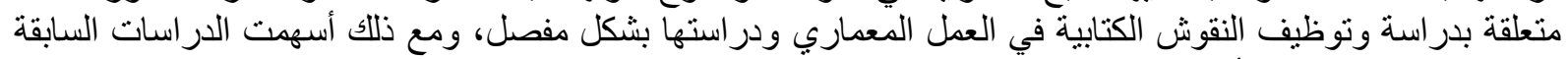

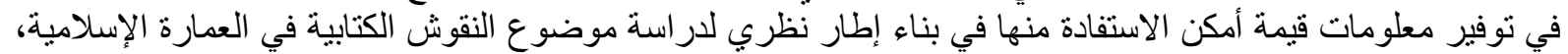

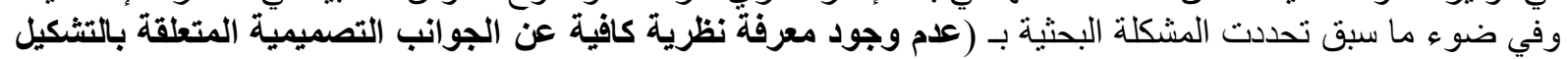

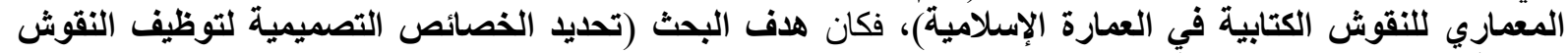

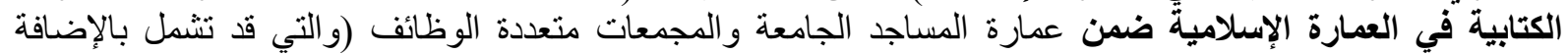
للمسجد مدرسة أو ضريح أو كليهما).

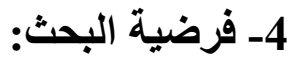

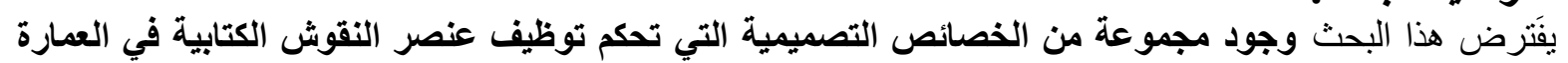

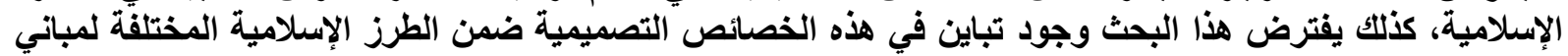

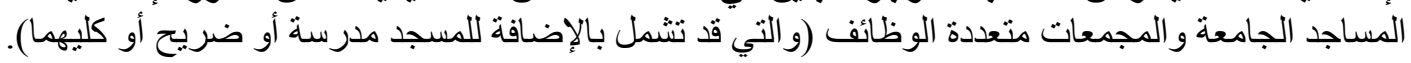

5- من منهج البحث: 1-1: بناء إطار نظري يضم مجموعة من المفردات المتعلقة بالخصائص التصميمية لتوظيف النقوش الكتابية في العمارة الإسلامية.

2-5: القيام بدر اسة عملية تحليلية لتوضيح تباين هذه الخصائص ضمن الطرز الإنس الإسلامية المختلفة لمباني المساجد الجامعة

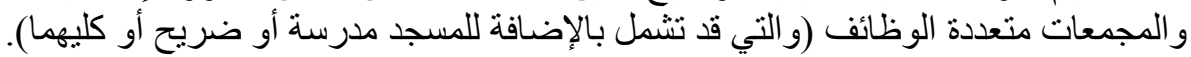

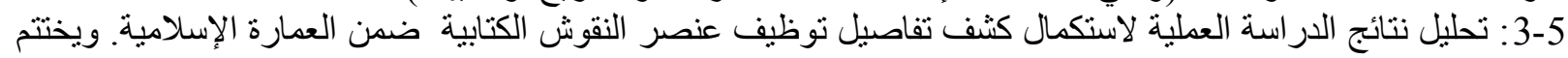
البحث بالإشارة إلى مجمو عة من الاستنتاجات و التوصيل

1-5: الإطار النظري للذصائص التصميمية للنقوش الكتابية في العمارة الإسلامية:

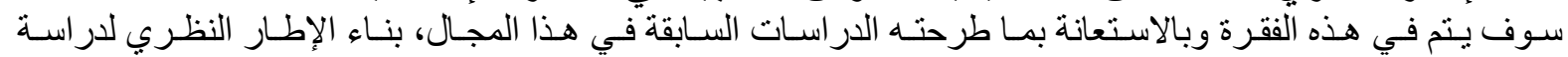

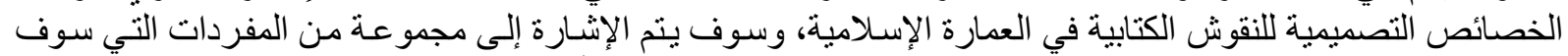
يعتمدها البحث لدر اسة موضوع النقوش الكتابية في العمارة الإسلامية، وكما يأني: 


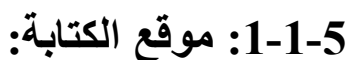

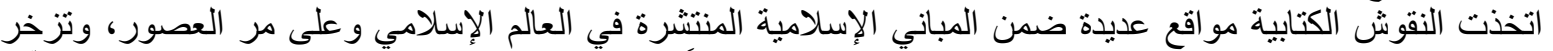

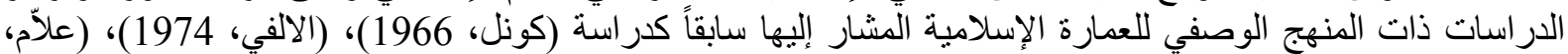

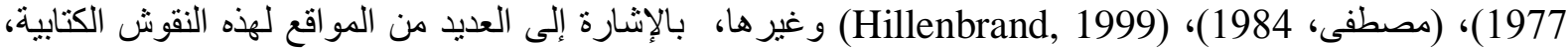

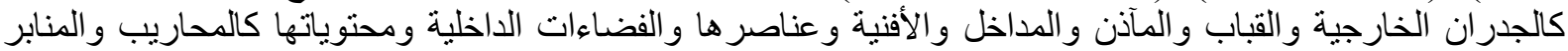

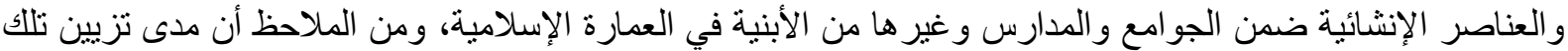

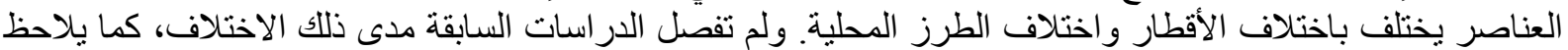

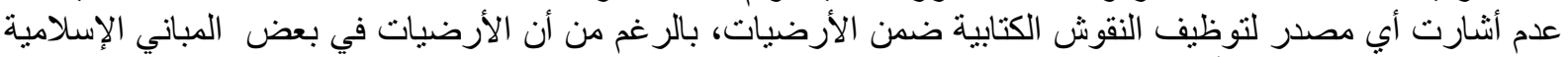

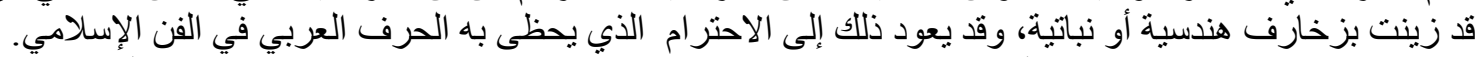

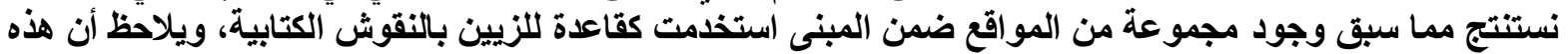

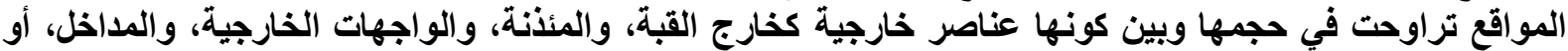

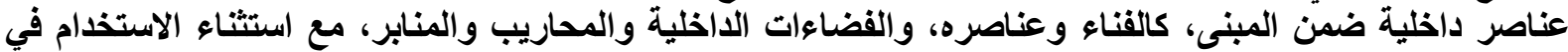

2-1-5 مواد وطريقة التنفيذ للنقوش الكتابية:

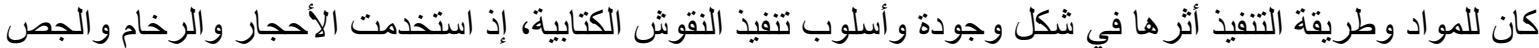

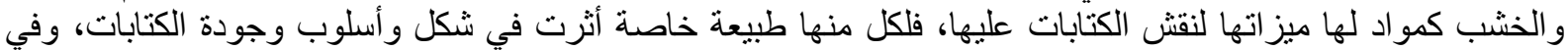

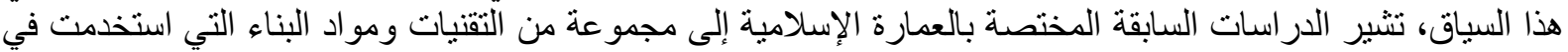

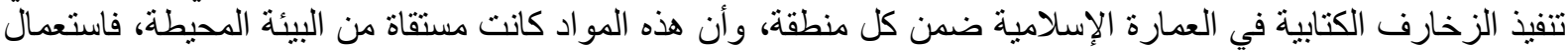

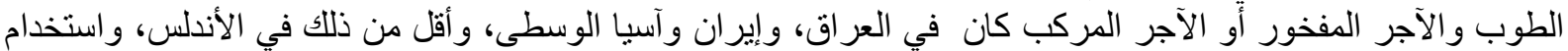

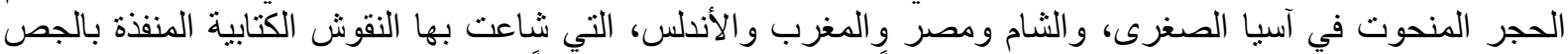

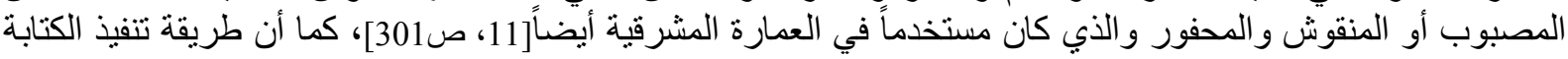

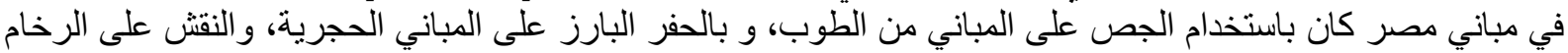

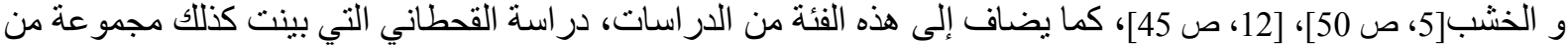

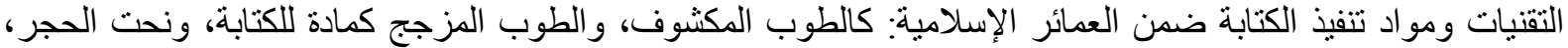

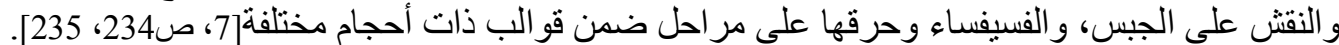

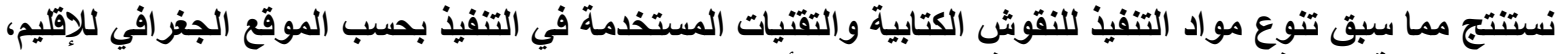

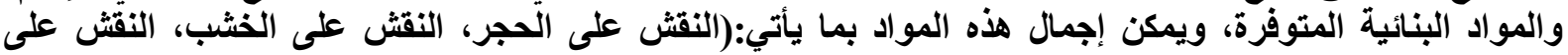
المعدن، والنقش عل الجص، الرسم على الجص، البلاطات المزججة، النقش على النى الطابوق، قطع الطابوق المزججة).

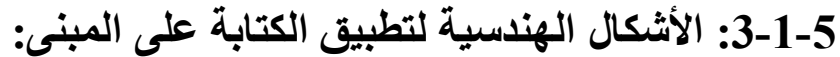

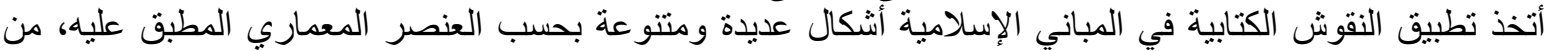

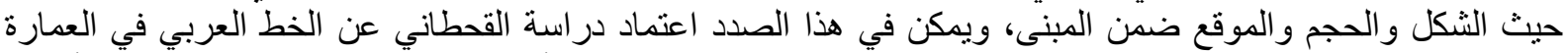

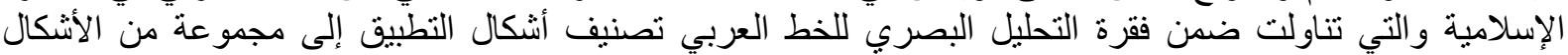

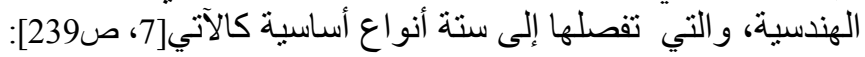

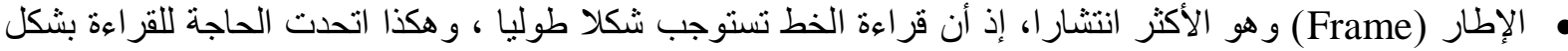

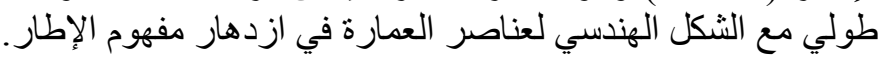

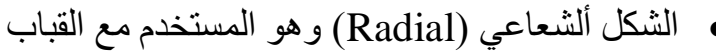

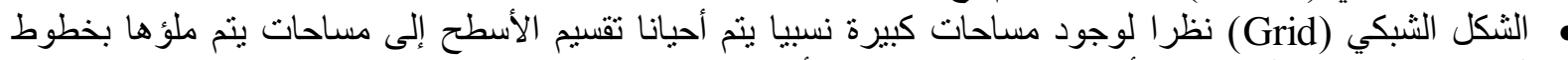

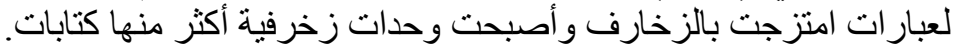

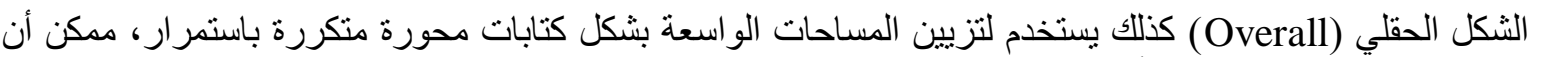

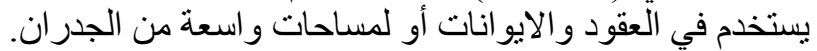

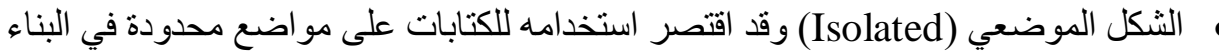

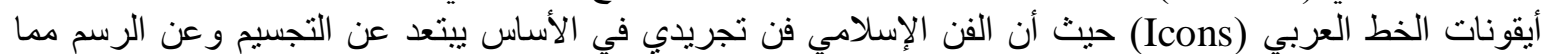
ساعد على أن تتحول بعض العبار ات (لفظ الجلالة أو اسم النبي الكريم مثثلا) إلى أيقونات توضع في في أماكن منميزة. 


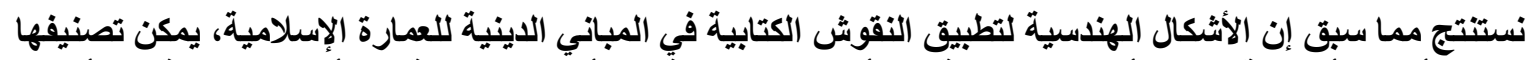

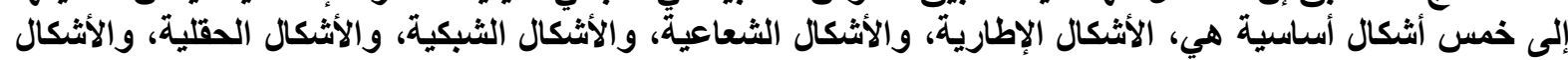
الموضعية، والأشكال الايقونية.

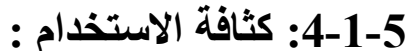

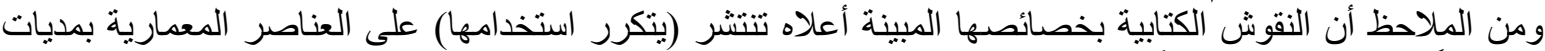

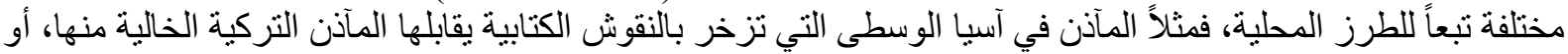

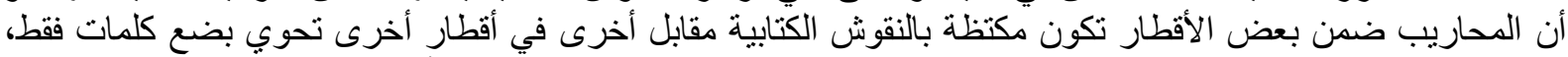

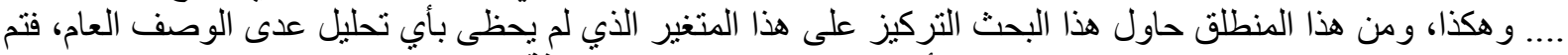

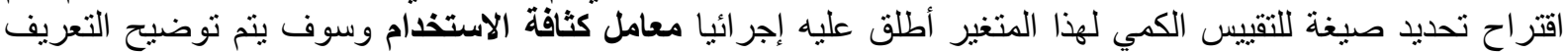
الإجر ائي لله وكيفية احتسابه ونطبيقه ضمن إجر اءات الأراسة العملية.

يضاف إلى المفردات السابقة مجموعة أخرى من المفردات متعلقة بالجوانب الفكرية والدلالية للنقوش الكتابية كالآتي:

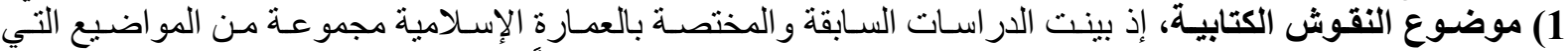

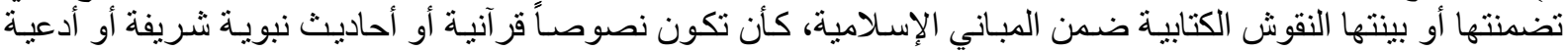

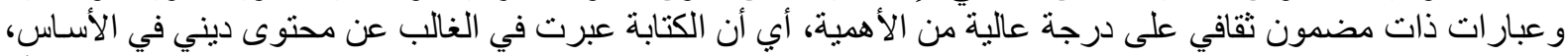

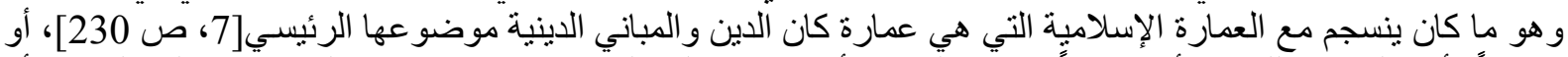

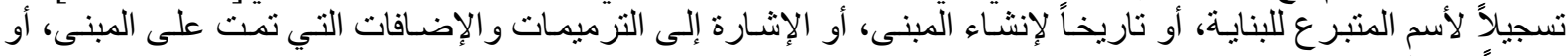

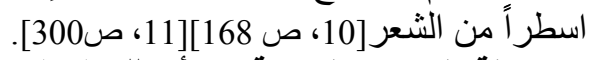

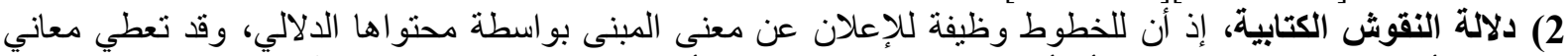

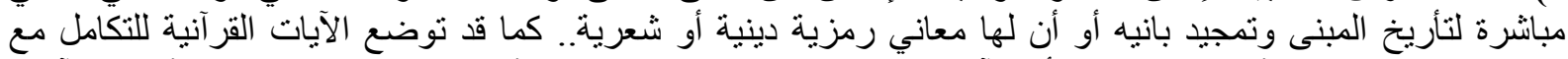

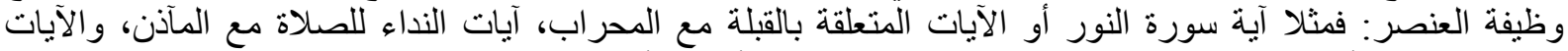

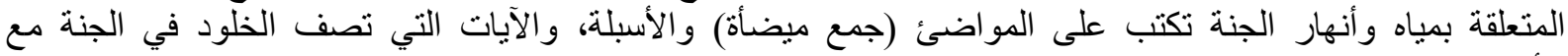

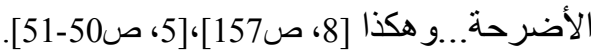

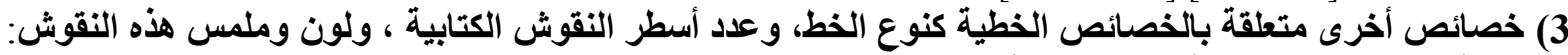

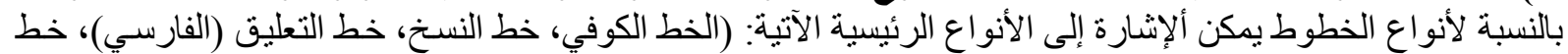

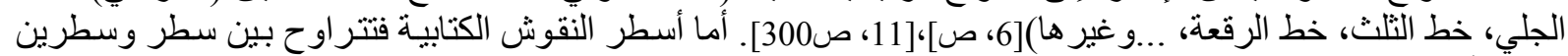

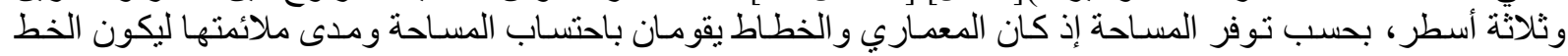

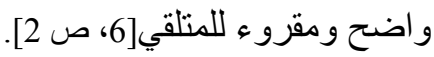

2-5 : تطبيق الإطار النظري (الدراسة العملية):

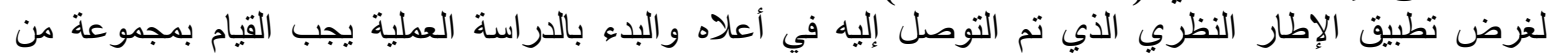

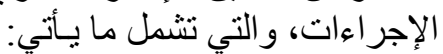

1-2-5

2-2-5 3-2-5

1-2-5

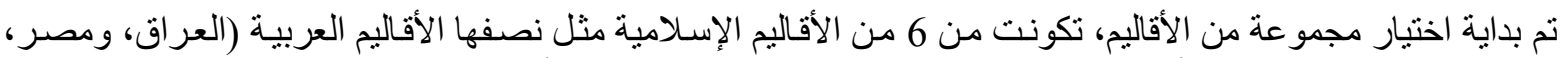

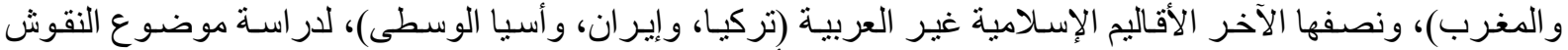

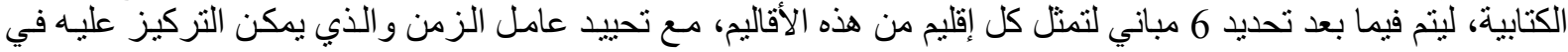

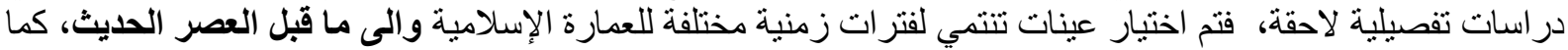
روعي في اختيار العينات توفر المعلومات الو افية لدر اسة كل عناصر ها المعمارية التي وظفت النقوش الكتابية فيها، ينظر

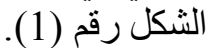


ذنون: الخصائص التصميمية للنقوش الكتابية في العمارة الإسلامية

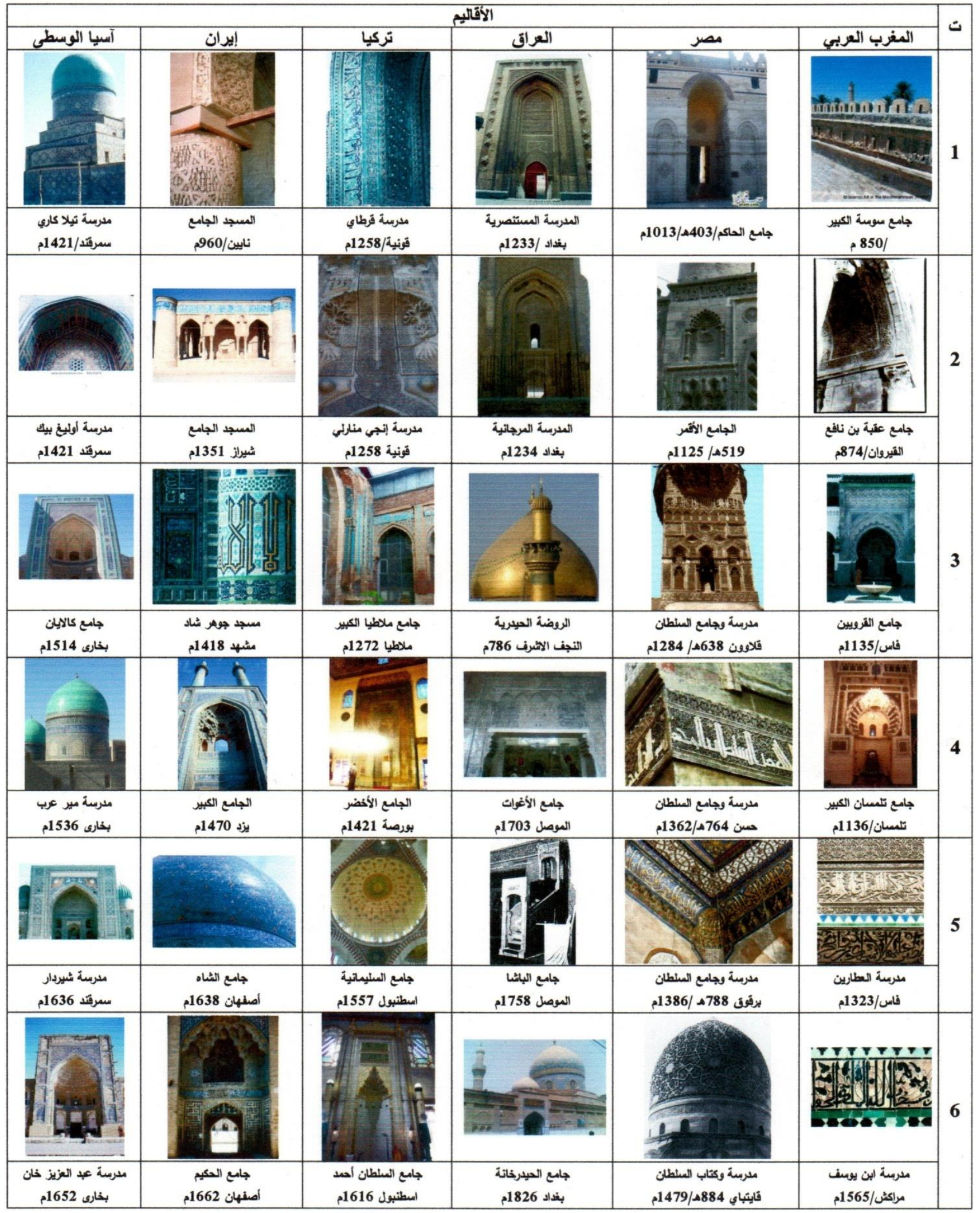

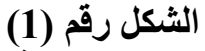

صور عينات الاراسة العملية 


\section{2-2-5}

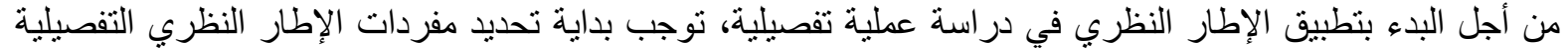

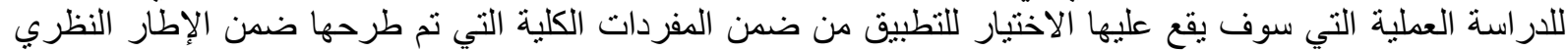

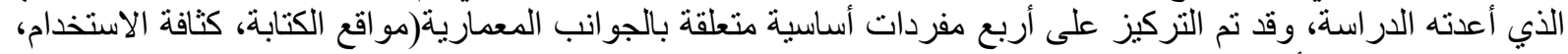

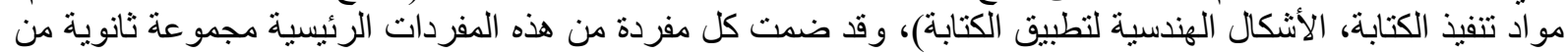

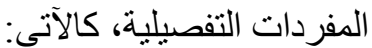

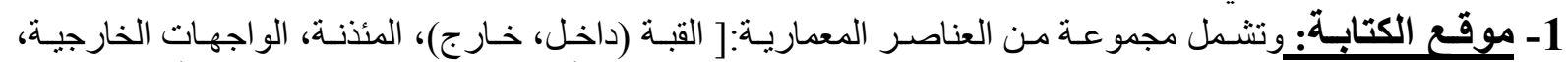

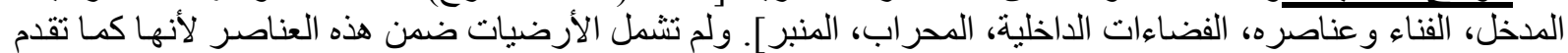

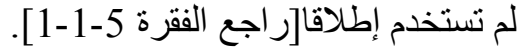

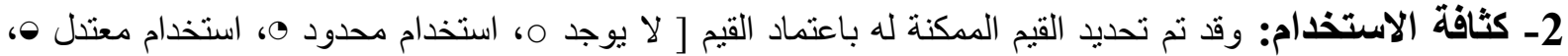

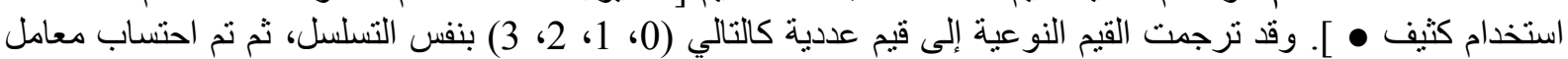

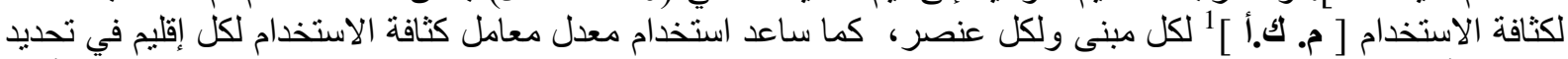

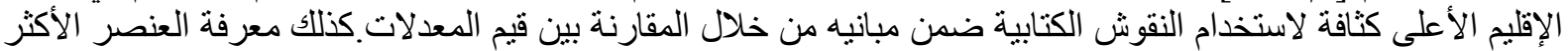

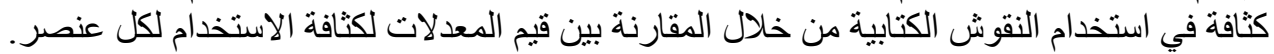

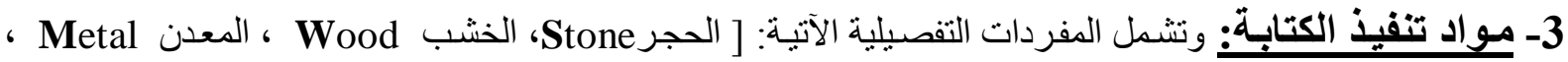

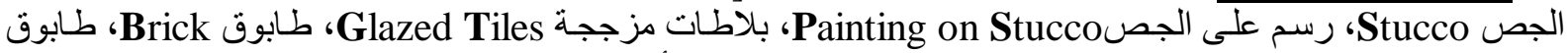

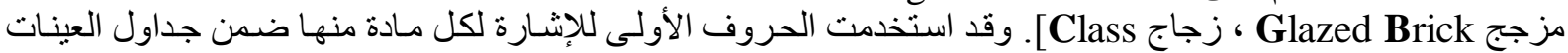
اللار اسة العملية.

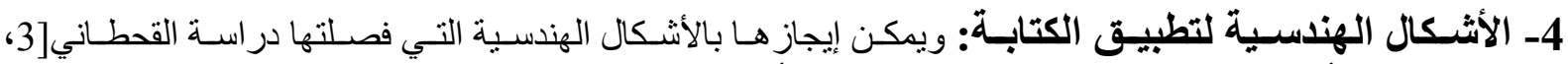

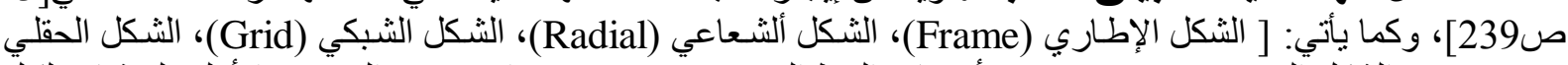

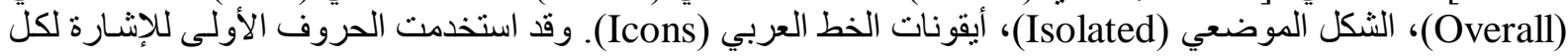

مادة منها ضمن جداول العينات للار اسة العملية. الثكل رقم (2).

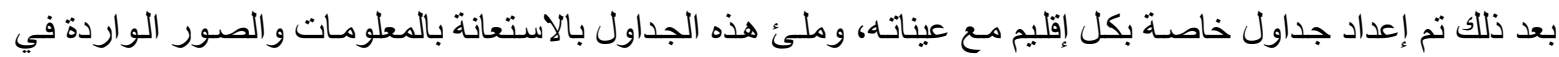

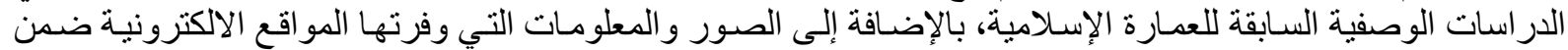

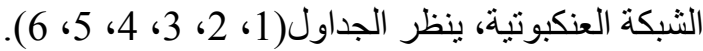

ملاحظة: نظر اً للعد الكبير من صور نماذج العينات التي تم استخدامها في البحث و التي زادت عن 300 صدورة، سوف

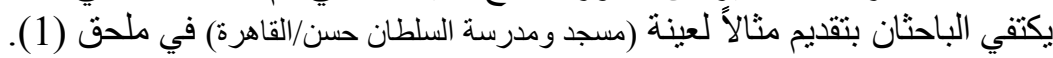

3-2-5

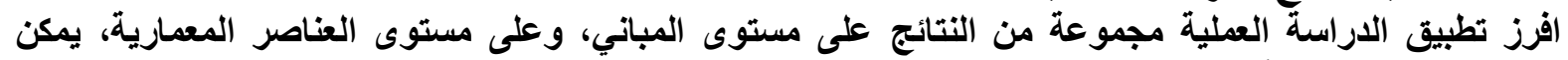

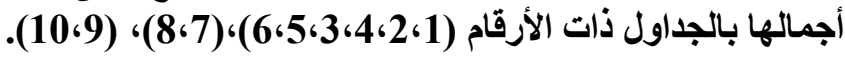

1 معامل كثافة الاستخدام[ م. ك.أ ]: هو مقياس أجرائي خاص بالبحث لتحديد مقدار التفاوت في كثافة انتشار النقوش

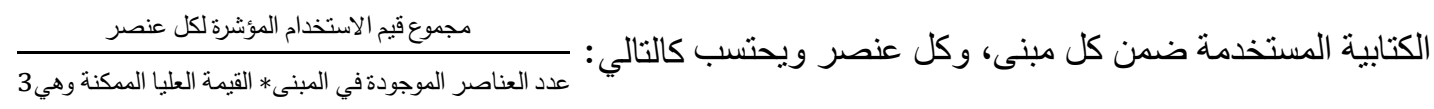

$$
\begin{aligned}
& \text { (إذ أن بعض المباني لا تضم جميع العناصر ، فمثلا بعضها لا يحتوي على مئنة أو محراب...الخ) }
\end{aligned}
$$

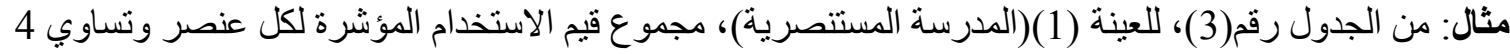

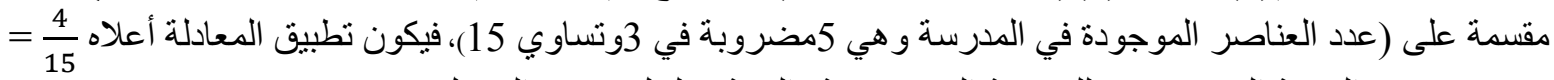

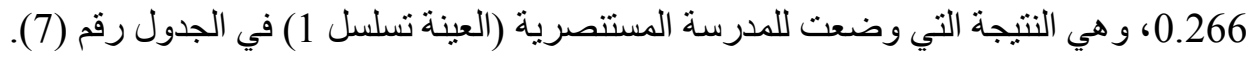




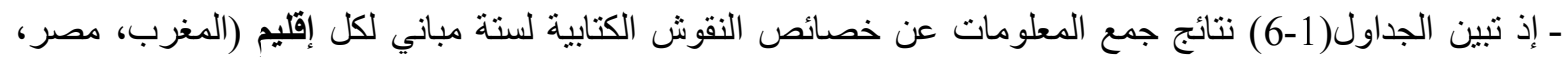

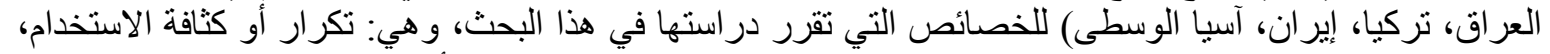

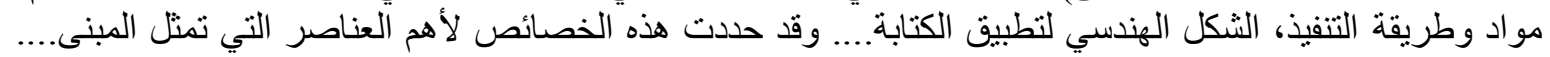

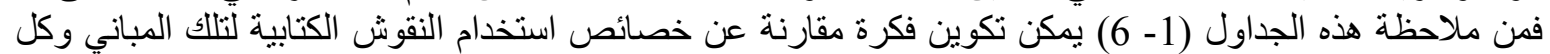

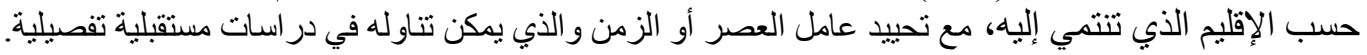

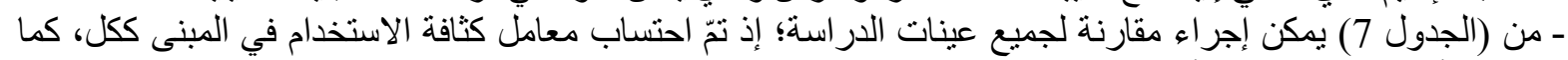

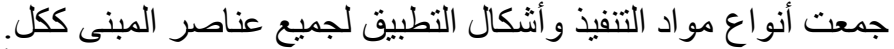

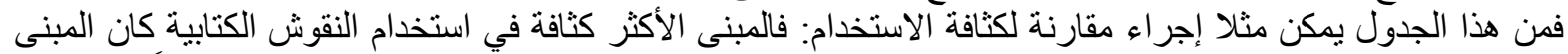

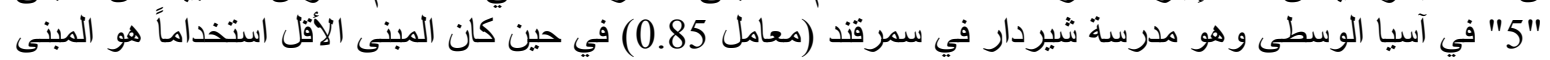

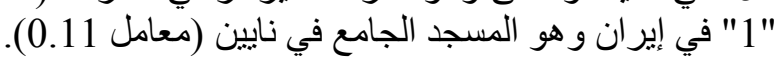

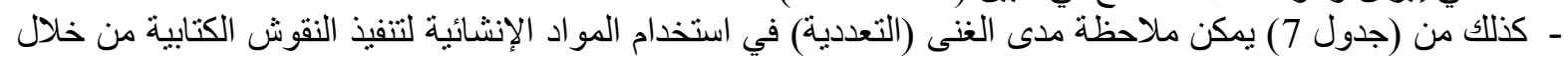

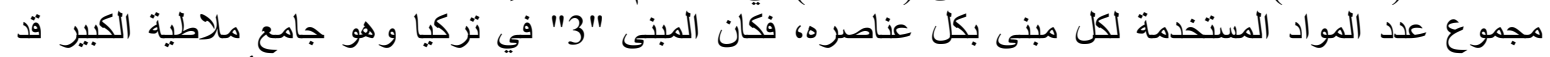

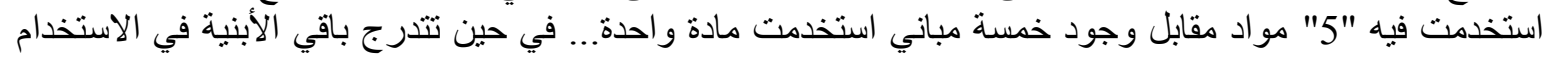

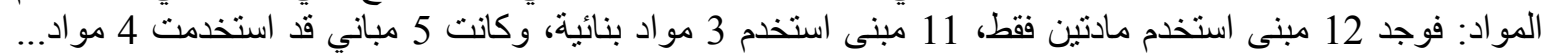

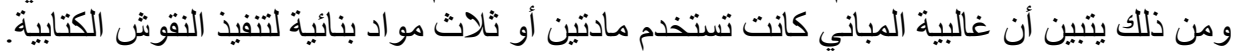

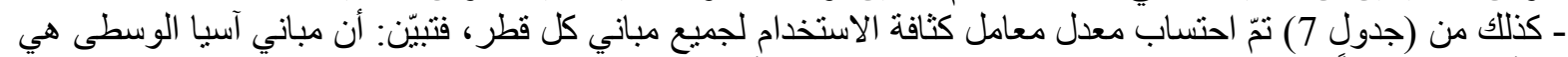

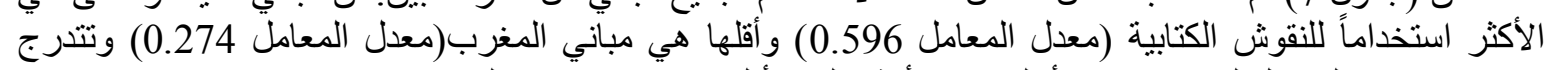

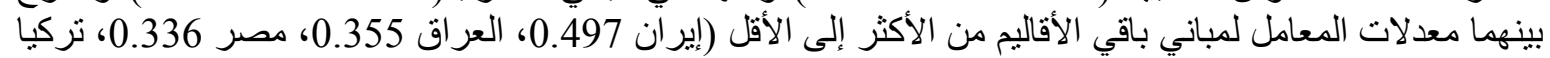

$(0.305$ ـ كذلك من (جدول 7) يمكن مقارنة تعددية استخدام أثكال تطبيق النقوش الكتابية بين مباني العينة من المبنى الذي وني

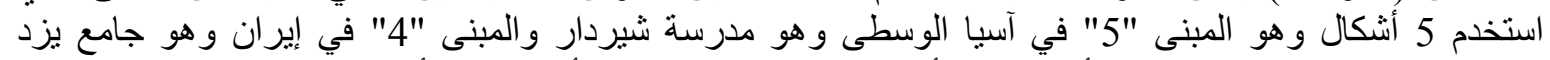

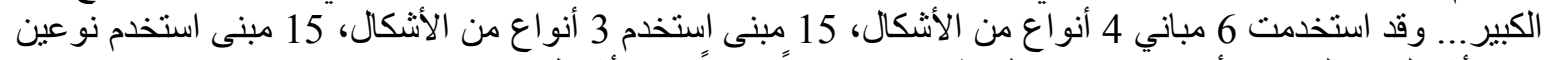

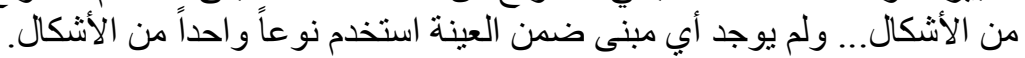

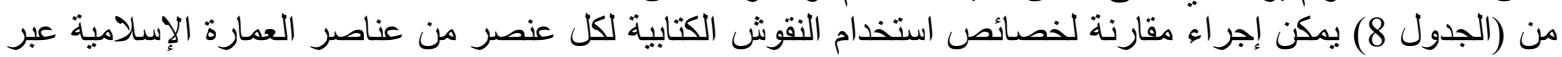

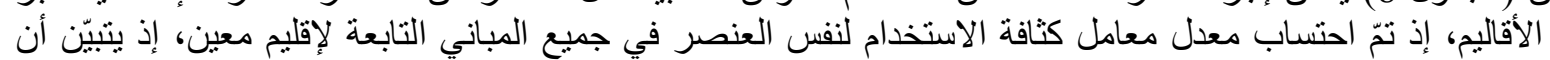

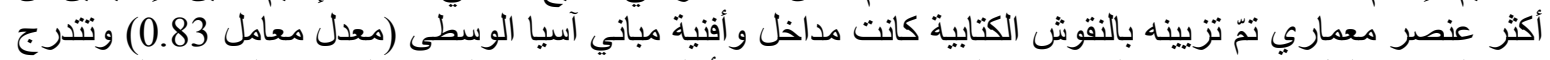

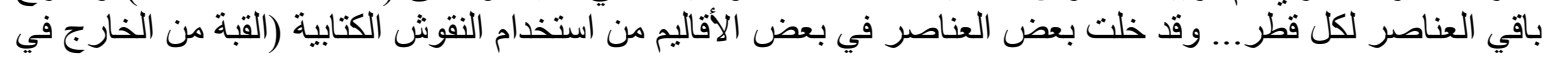

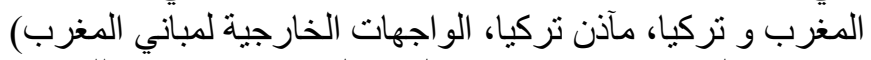

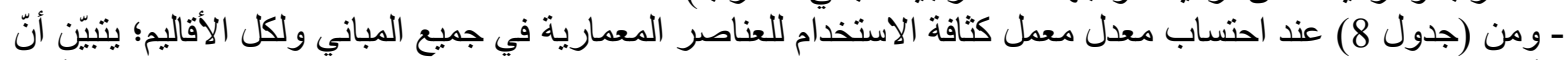

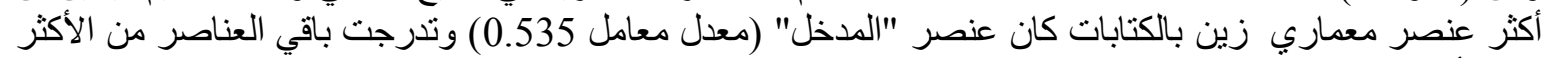

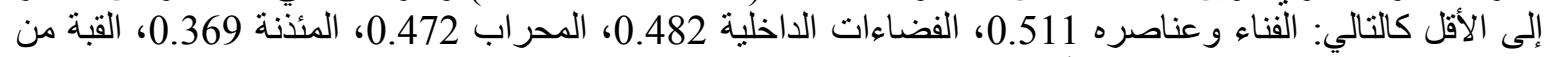

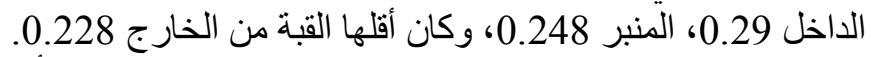

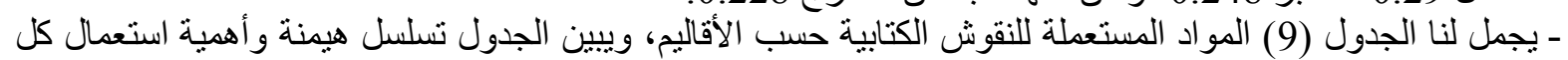

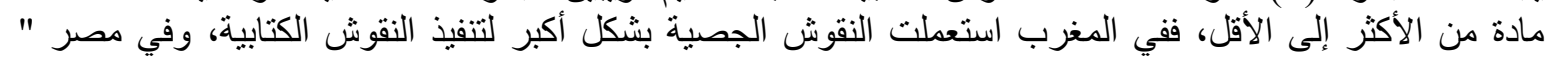

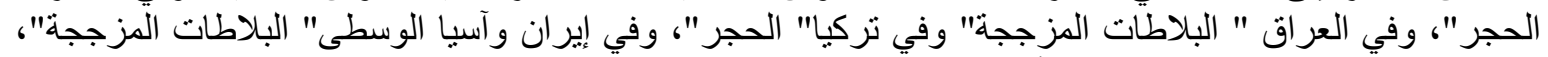

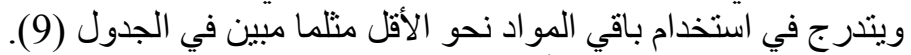

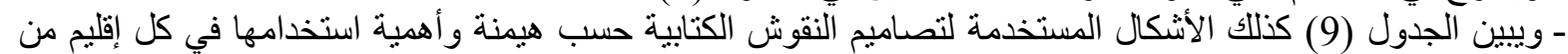

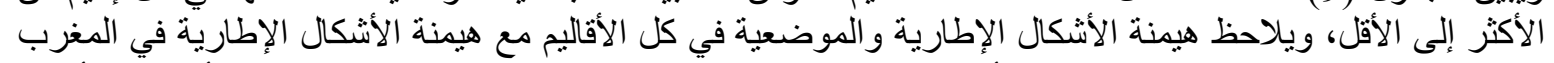

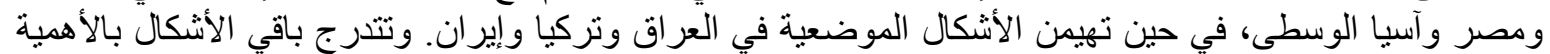

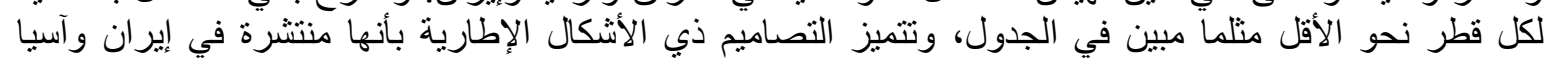
الوسطى فقط.

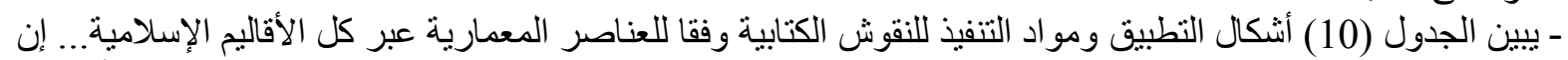

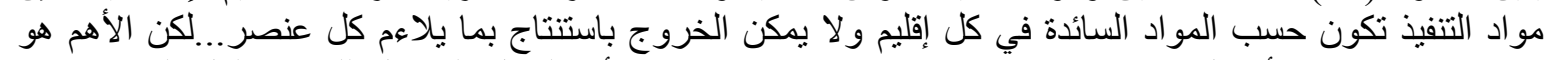

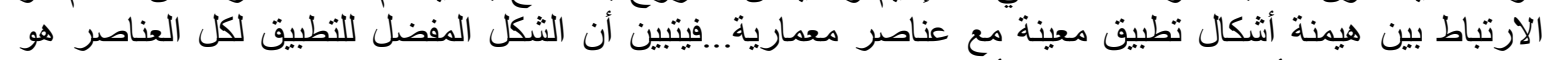

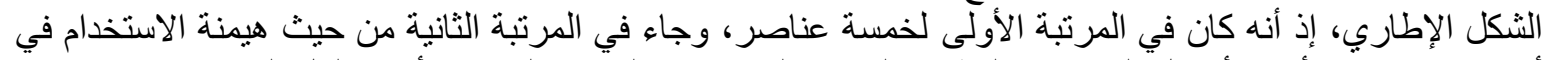

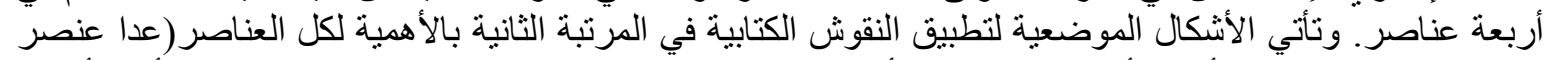

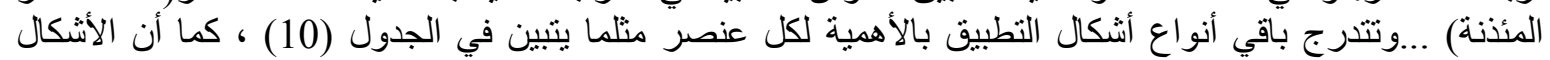




\section{$\begin{array}{lllll}\text { Al-Rafidain Engineering } & \text { Vol.21 } & \text { No. } 6 & \text { December } & 2013\end{array}$}

الثعاعية ينحصر وجودها في القباب من الداخل وفي المحاريب (في الجزء المحدب منها) فقط.. في حين أن الأشكال

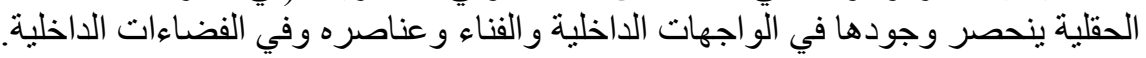

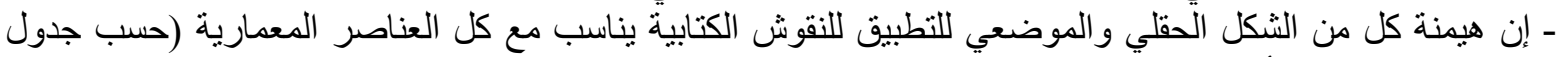
10)، وكذللك عبر الأقطار الإسلامية (حسب الجدول9).

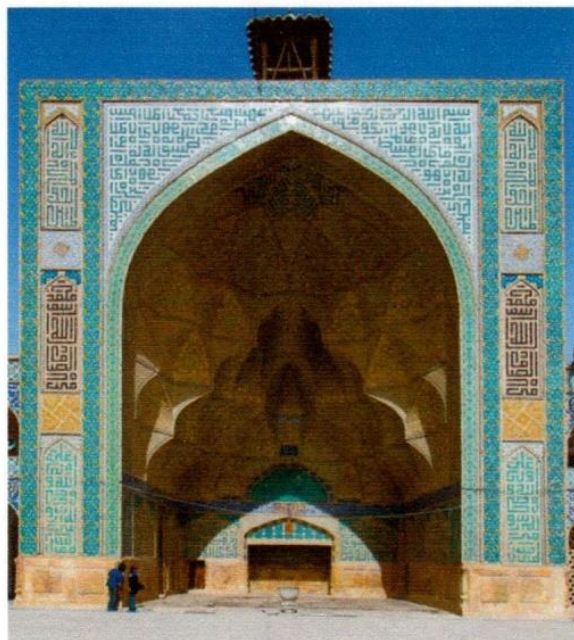

(ائشكال العقلية (Overall) إيوان مسجد الجمعة/أصفهان الانكان

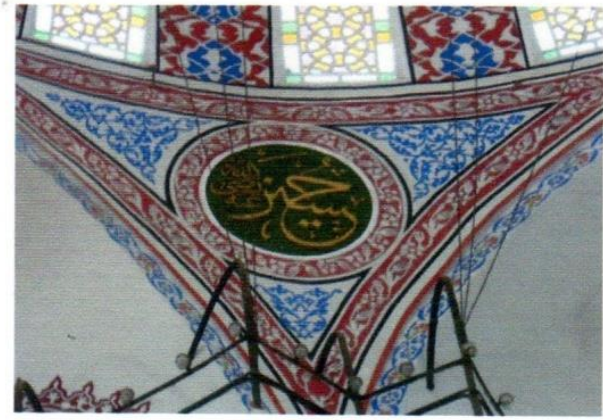

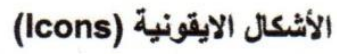

داخل قبة جامع سلطان أحمد/اسطنبول الايقان

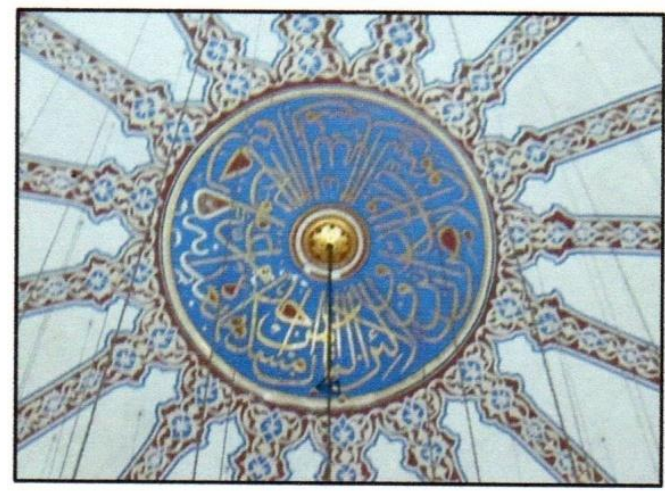

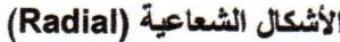

السقف الداخلي لقبة جامع سلطان أحمد/أسطنبول
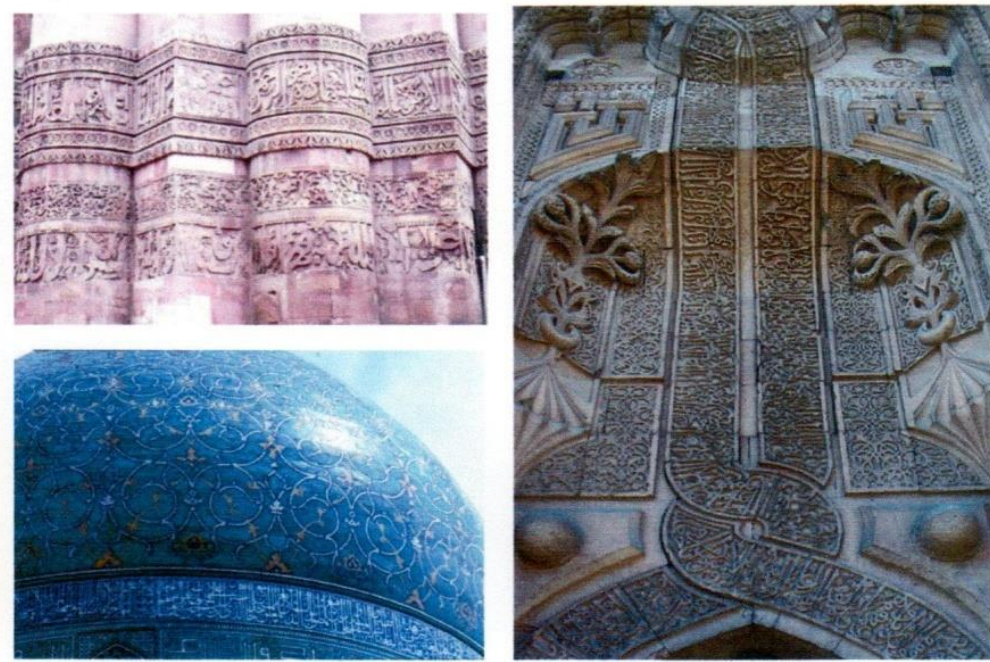

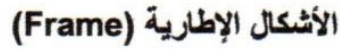

مدخل مدرسة انجي منارلي/قونية، مئذنة قطب منارة/ الهند، قبة جامع الثاه/أصفهان
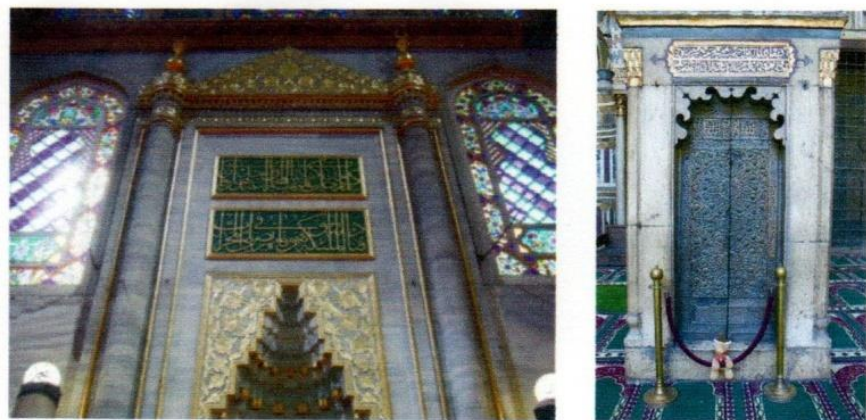

الأشكال الموضعية (Isolated)

منبر مسجد ومدرسة السلطان حسن/القاهرة، محراب جامع سلطان أحمد/اسطنبول
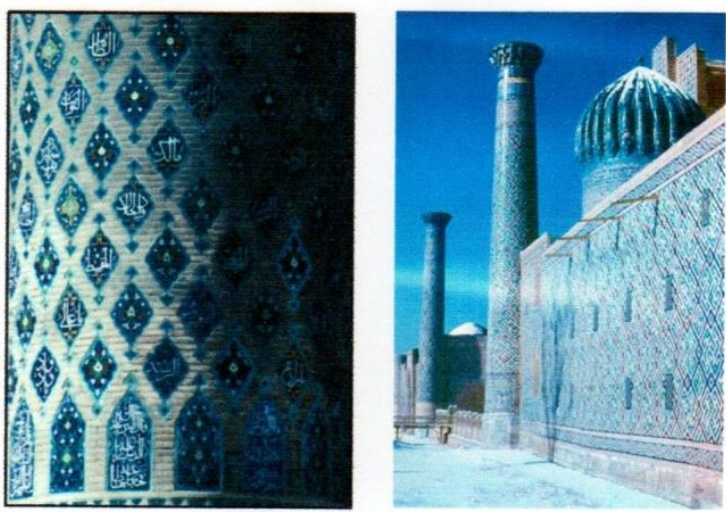

(Grid) الأشكال الشبكية (1)

مدرسة شير ودور/سمرقند، مسجد جوهر شاد/ايران

(2) الشكل رقم (2)

الأثكال الهندسية لتطبيق النقوش الكتابية رقم 
ذنون: الخصائص التصميمية للنقوش الكتابية في العمارة الإسلامية

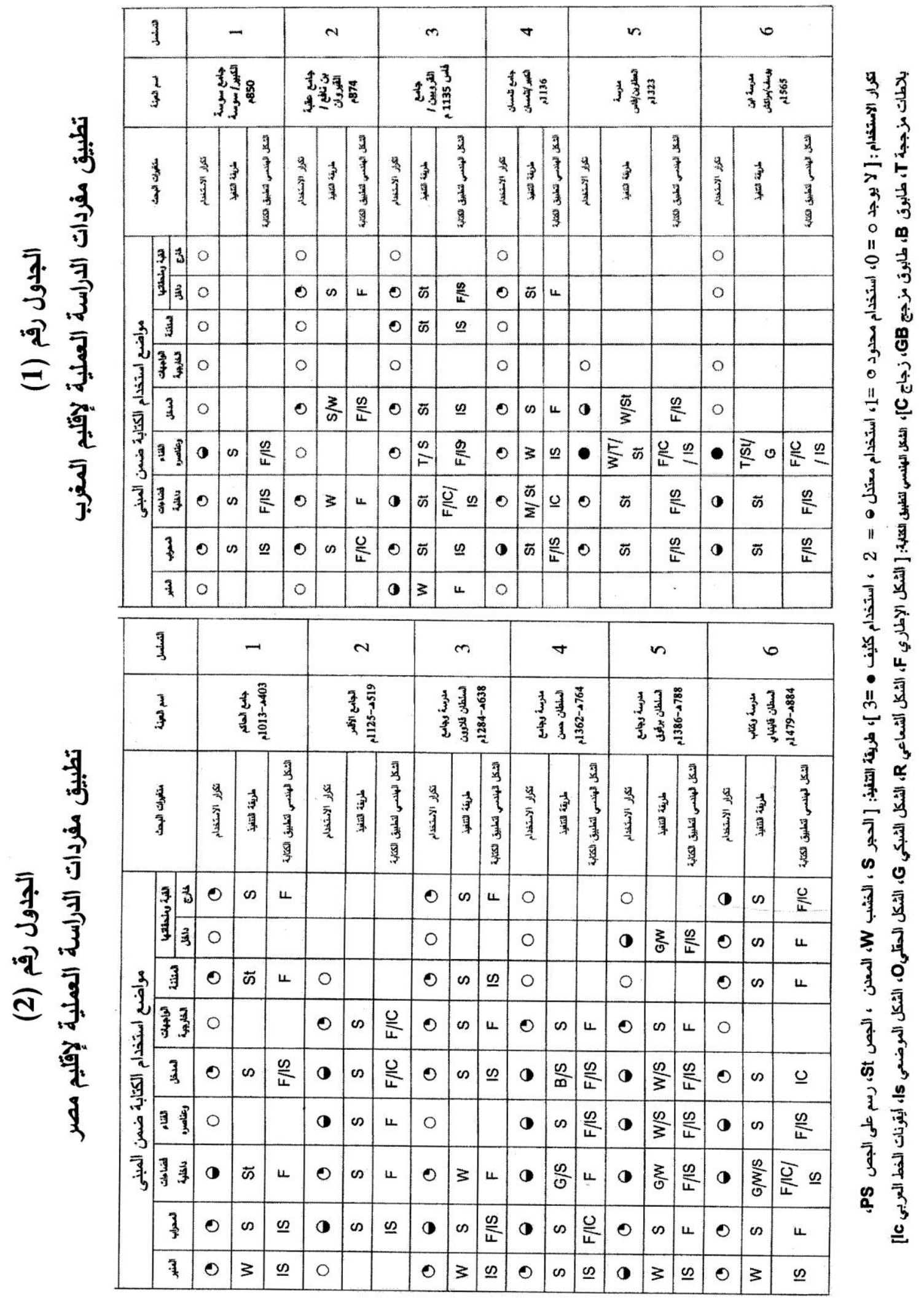


No. 6

December

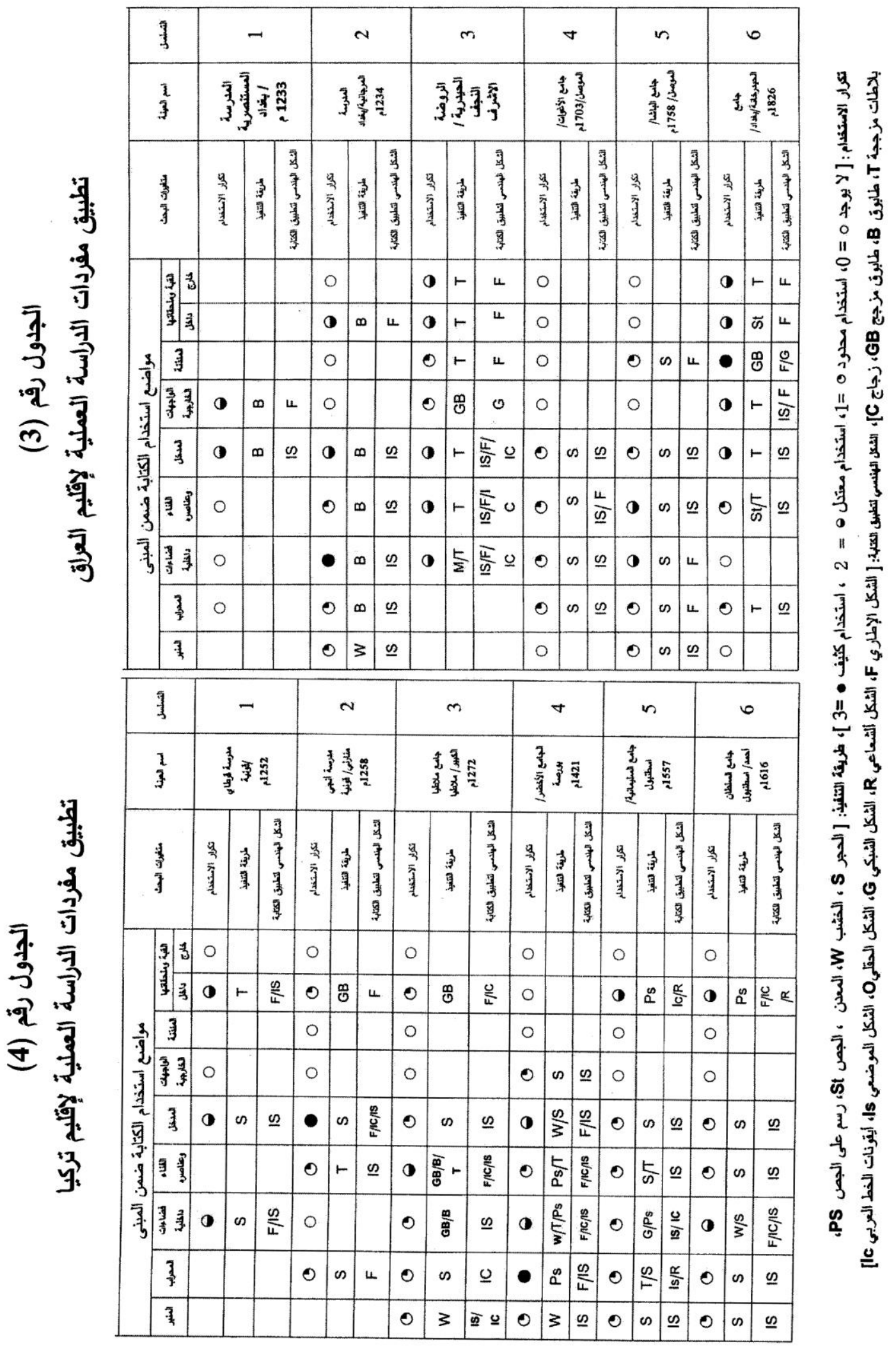


ذنون: الخصائص التصميمية للنقوش الكتابية في العمارة الإسلامية

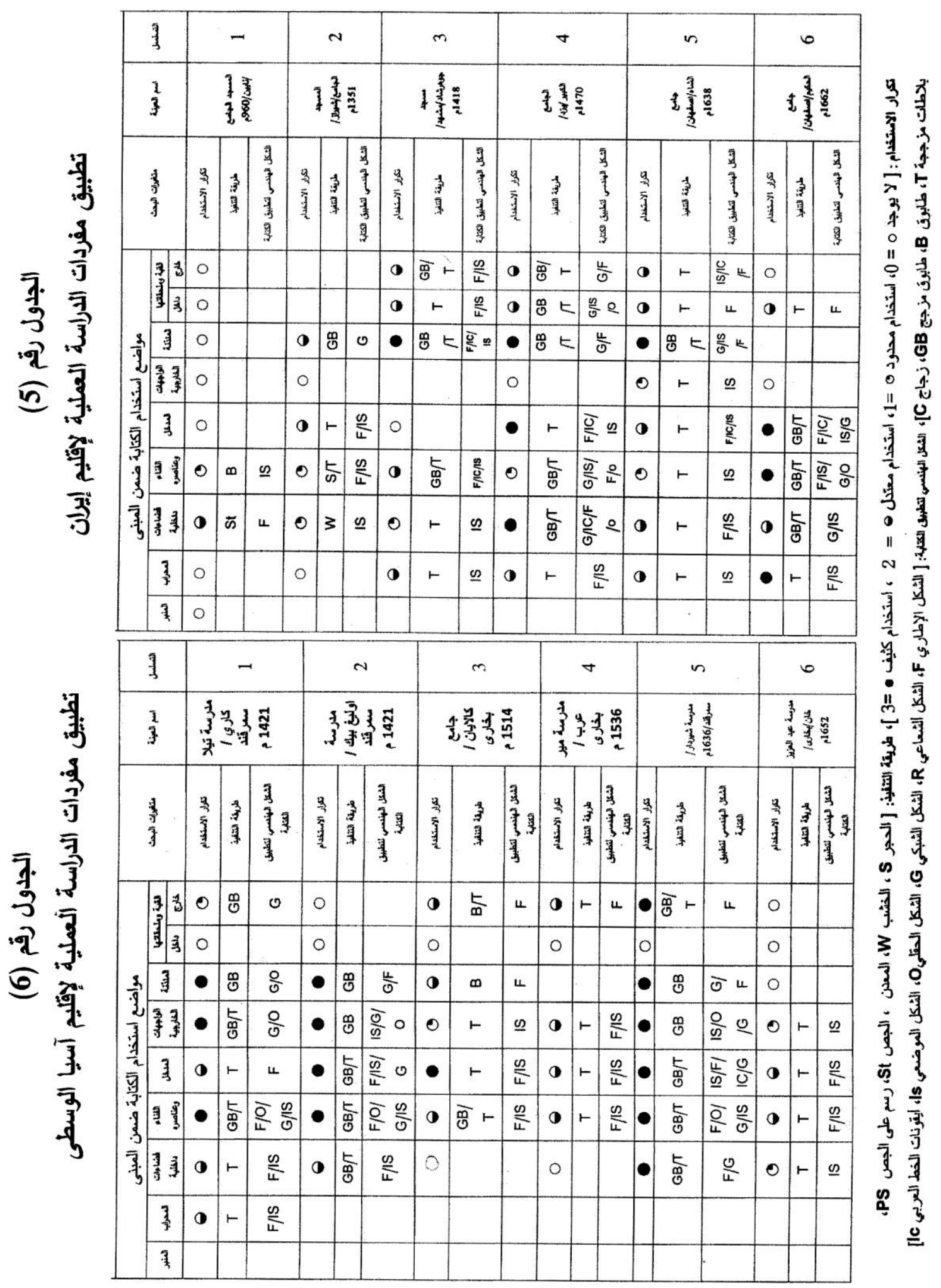


No. 6

December 2013

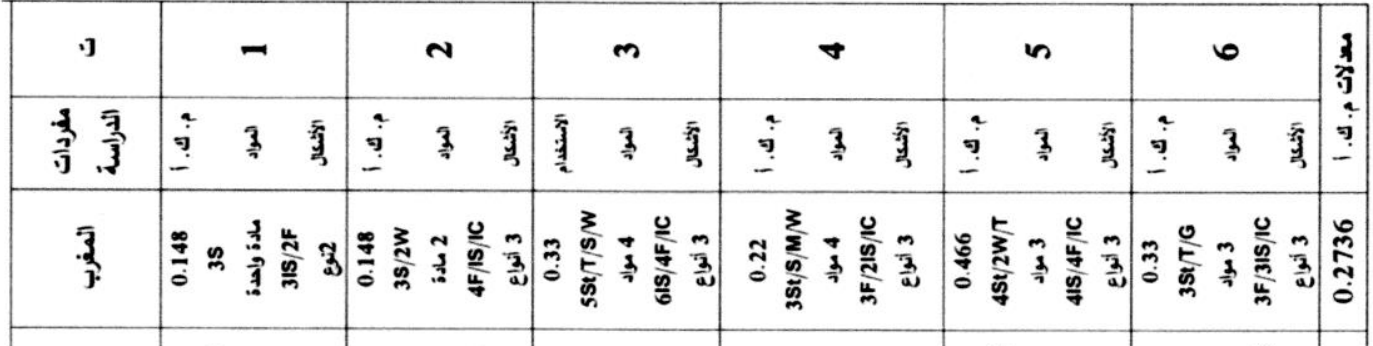

1.

종.

畓

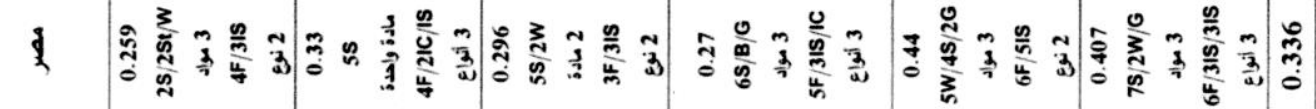

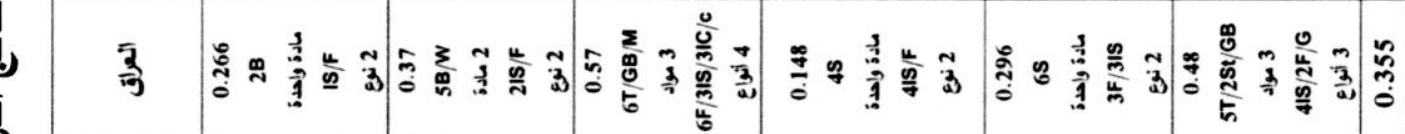

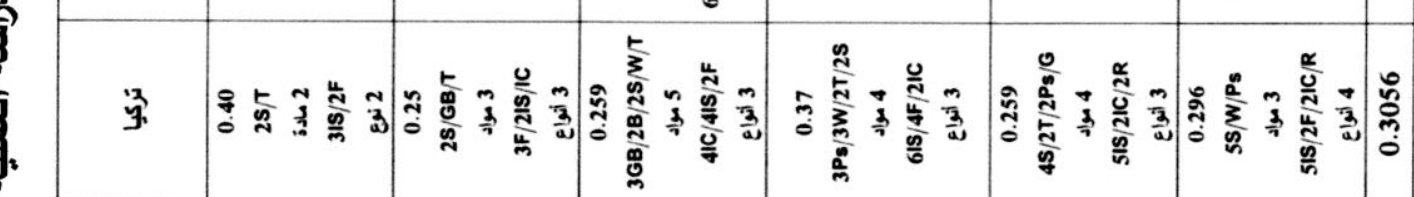

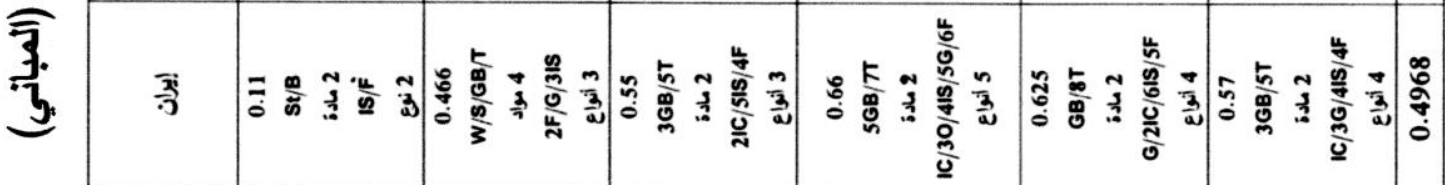

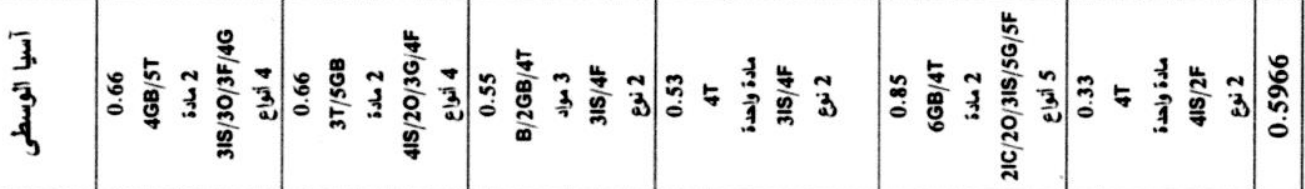

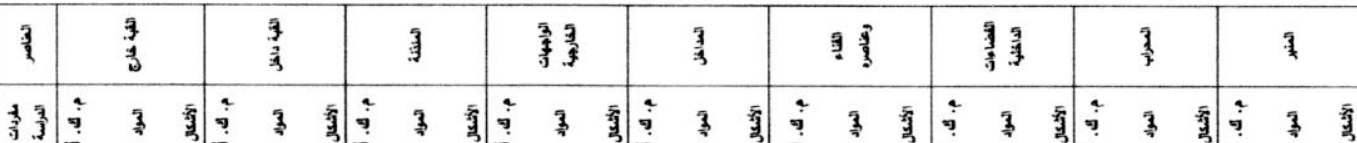

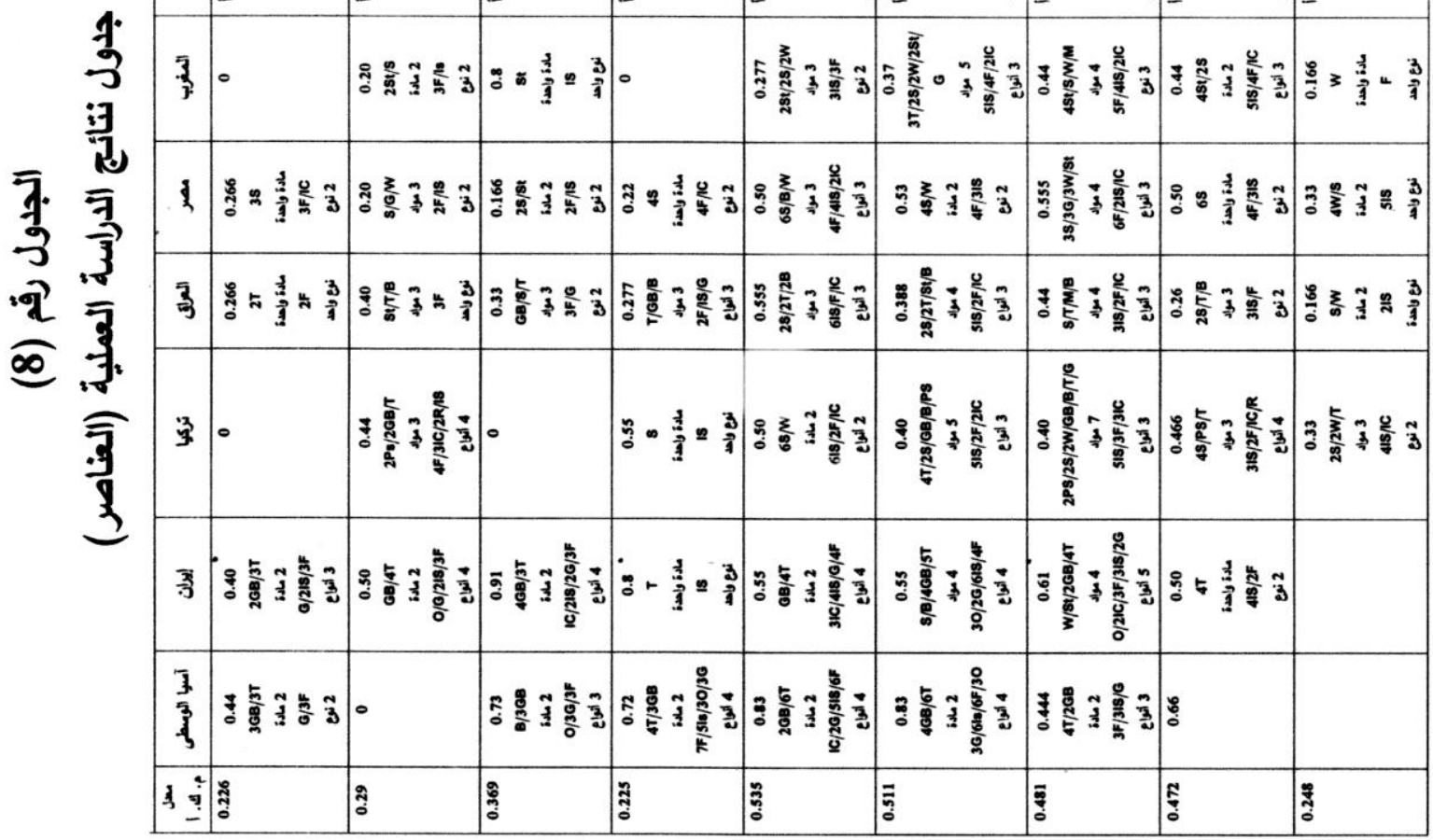




\section{الجدول رقم (9)}

نتائج الدراسة العملية للمواد والأشكال الأكثر استخداماً على مستوى الأقاليم

\begin{tabular}{|c|c|c|c|c|c|c|c|c|c|c|c|c|}
\hline \multicolumn{2}{|c|}{ الميا الوسطى } & \multicolumn{2}{|c|}{ إيرلن } & \multicolumn{2}{|c|}{ تركيا } & \multicolumn{2}{|l|}{ العلت } & \multicolumn{2}{|c|}{ مصر } & \multicolumn{2}{|c|}{ المغرب } & \\
\hline \multirow{2}{*}{\multicolumn{2}{|c|}{$\begin{array}{l}\text { 24T } \\
\text { أططع الطابوق } 17 G B\end{array}$}} & \multirow{7}{*}{\multicolumn{2}{|c|}{ 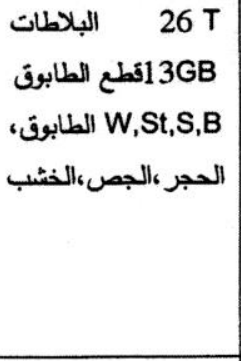 }} & الحجر & $17 \mathrm{~s}$ & \multirow{7}{*}{\multicolumn{2}{|c|}{ 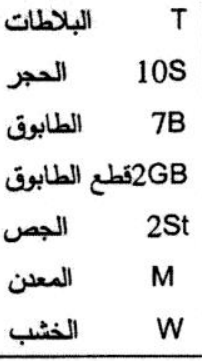 }} & \multirow{7}{*}{ الزال الزجبر } & \multirow{7}{*}{$\begin{array}{c}29 \mathrm{~S} \\
10 \mathrm{~W} \\
4 \mathrm{G} \\
2 \mathrm{St} \\
\mathrm{B}\end{array}$} & \multirow{7}{*}{\multicolumn{2}{|c|}{ 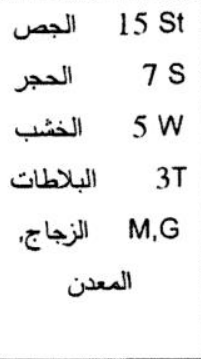 }} & \multirow{7}{*}{ المواد } \\
\hline & & & & البلاطات & $7 \mathrm{~T}$ & & & & & & & \\
\hline \multirow[t]{5}{*}{ الطابوق } & \multirow[t]{5}{*}{ B } & & & \multicolumn{2}{|c|}{ 6Ps رسم ع الجص } & & & & & & & \\
\hline & & & & الخُبب & & & & & & & & \\
\hline & & & & ع الطابوق & $4 G B$ & & & & & & & \\
\hline & & & & الطابوق & B & & & & & & & \\
\hline & & & & الزجاج & G & & & & & & & \\
\hline الإطارية & $22 \mathrm{~F}$ & الموضعية & $231 \mathrm{~S}$ & الموضعية & $251 S$ & الموضعية & 2015 & الإطارية & $28 \mathrm{~F}$ & الاطارية & $20 \mathrm{~F}$ & \\
\hline الموضعية & 2015 & الإطارية & $22 \mathrm{~F}$ & الإطارية & $13 F$ & الاططارية & $11 \mathrm{~F}$ & الموضعية & $181 S$ & الموضعية & 1715 & \\
\hline الشبكية & $12 G$ & الشبكية & $10 \mathrm{G}$ & الايقونية & $111 \mathrm{C}$ & الايقونية & $91 \mathrm{C}$ & الايقونية & $61 \mathrm{C}$ & الايقونية & & الأمثكال \\
\hline الحقلية & 70 & الايقونية & $6 I C$ & المُعاعية & $3 R$ & الثبعاعية & & & & & & \\
\hline الايقونية & $2 \mathrm{IS}$ & الحقلية & 30 & & & & & & & & & \\
\hline
\end{tabular}

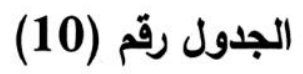

نتائج الدراسة العملية للمواد والأشكال الأكثر استخداماً على مستوى العناصر

\begin{tabular}{|c|c|c|c|c|c|c|c|c|c|c|}
\hline \multicolumn{5}{|c|}{ مواد التنفيذ } & \multicolumn{5}{|c|}{ الأشُكال } & \multirow{2}{*}{ القبة خارج } \\
\hline & . & $\begin{array}{l}\text { العجر } \\
3 S\end{array}$ & $\begin{array}{c}\text { 5GB } \\
\text { كع الطابوف }\end{array}$ & $\begin{array}{c}9 T \\
\text { البلاطلات }\end{array}$ & & & $\begin{array}{l}\text { IC } \\
\text { ايقونية }\end{array}$ & $\begin{array}{l}\text { 2G,2IS } \\
\text { الثبكية } \\
\text { الثبعية }\end{array}$ & $\begin{array}{l}11 F \\
\text { إطارية }\end{array}$ & \\
\hline & $\begin{array}{c}\text { G,W,B } \\
\text { طابوق،خشب، زهاج }\end{array}$ & 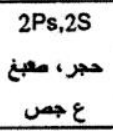 & 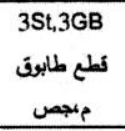 & $\begin{array}{c}6 \mathrm{~T} \\
\text { البلاطلات }\end{array}$ & 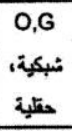 & $\begin{array}{l}2 R \\
\text { ثبعاعية }\end{array}$ & $\begin{array}{l}\text { ايقونية } \\
3 \mid C\end{array}$ & مIS & $\begin{array}{l}15 F \\
\text { إطارية }\end{array}$ & القبة داخل \\
\hline $\begin{array}{c}\text { B } \\
\text { طابوت }\end{array}$ & $\begin{array}{l}2 S t \\
\text { جص }\end{array}$ & حجر & $\begin{array}{c}4 T \\
\text { البلاطات }\end{array}$ & $\begin{array}{c}\text { 8GB } \\
\text { تطع طابوق }\end{array}$ & & $\begin{array}{c}\text { O.IC } \\
\text { ايقونية، حقلية }\end{array}$ & $\begin{array}{l}\text { 4IS } \\
\text { موضعية }\end{array}$ & $\begin{array}{c}6 G \\
\text { الشبكية }\end{array}$ & $\begin{array}{l}11 F \\
\text { !بارية }\end{array}$ & المنذنة \\
\hline & $\begin{array}{c}\text { B } \\
\end{array}$ & $\begin{array}{c}4 G B \\
\text { كطع طابوق }\end{array}$ & همر & $\begin{array}{c}6 T \\
\text { البلاكل }\end{array}$ & $\begin{array}{c}\text { IC } \\
\end{array}$ & 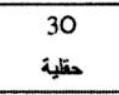 & $\begin{array}{c}4 G \\
\end{array}$ & $\begin{array}{c}8 \mathrm{IS} \\
\text { موضعية }\end{array}$ & $\begin{array}{l}13 F \\
\text { إطارية }\end{array}$ & الخارجية الولة \\
\hline ج جص & $\begin{array}{c}\text { 3GB,3B } \\
\text { طابوت تمطع طابوق }\end{array}$ & كنب & $\begin{array}{c}12 T \\
\text { البلاطات }\end{array}$ & عجر & & $\begin{array}{c}3 G \\
\text { الثبكية }\end{array}$ & $\begin{array}{l}81 C \\
\text { ايقونية }\end{array}$ & $\begin{array}{l}18 F \\
\text { !ٕلطارية }\end{array}$ & موضعية $281 S$ & المداخل \\
\hline $\begin{array}{c}\text { G.PS } \\
\text { صبن، زجاج }\end{array}$ & $\begin{array}{c}\text { 3W,3B,3ST } \\
\text { حص سطابوق،فّب }\end{array}$ & $\begin{array}{c}9 G B \\
\text { تطع طابوق }\end{array}$ & حجر & $\begin{array}{c}20 T \\
\text { البلاطلات }\end{array}$ & & $\begin{array}{c}\text { ايقونية شنبكية } \\
\end{array}$ & $\begin{array}{l}60 \\
\text { حقلية } \\
\end{array}$ & $\begin{array}{l}22 F \\
\text { إطارية }\end{array}$ & موضعية 3015 & وعناصر ه الفناء \\
\hline 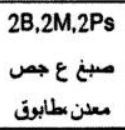 & زجاج & 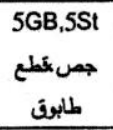 & 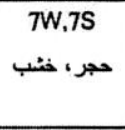 & $\begin{array}{c}\text { البلاطات } \\
\text { البات }\end{array}$ & $\begin{array}{c}0 \\
0 \text { حقلة }\end{array}$ & $\begin{array}{l}3 G \\
\text { شبكية }\end{array}$ & $\begin{array}{l}\text { ايتونية } \\
\text { IIC }\end{array}$ & موضعية $201 S$ & $\begin{array}{l}\text { ! طارية } \\
\end{array}$ & الفضارجية الفات \\
\hline & $\begin{array}{c}\text { B,Ps } \\
\text { مبغ ، طابوق }\end{array}$ & 4St & $\begin{array}{c}6 \mathrm{~T} \\
\text { البلاطات }\end{array}$ & عجر & & $\begin{array}{l}\text { R } \\
\end{array}$ & $\begin{array}{l}\text { ايقونية } \\
\end{array}$ & $\begin{array}{l}\text { إطارية } \\
\end{array}$ & موضعبة & المحراب \\
\hline & & $\begin{array}{c} \\
\end{array}$ & حجر & كثب & & & & $\begin{array}{l}\text { IC,F } \\
\text { إيقاريةية }\end{array}$ & موضعية & المنبر \\
\hline
\end{tabular}


1.

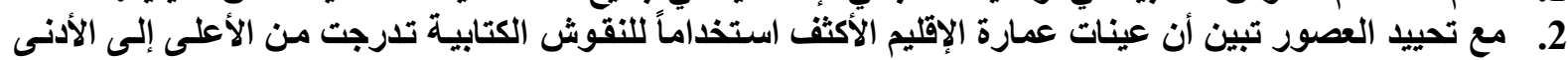

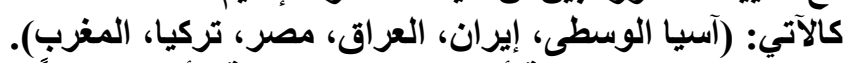

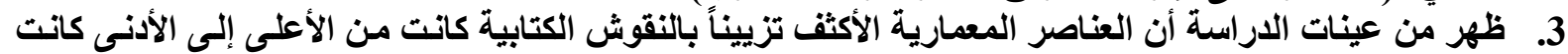

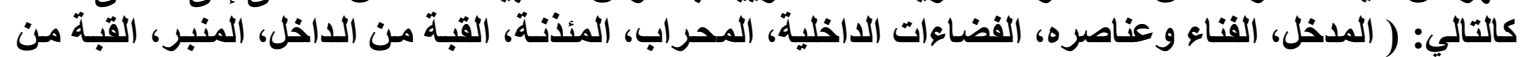

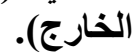
4. تبين أن الثكل المفضل لتطبيق النقوش الكتابية لكل العناصر هي الأثكال الإطارية، وجاء بعده في التفضيل الأثكال

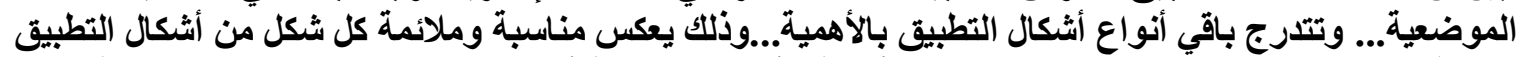

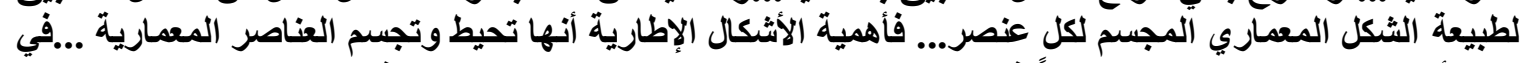

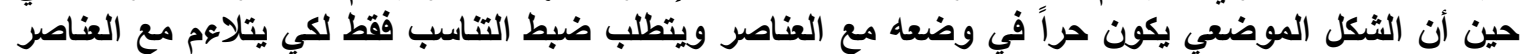

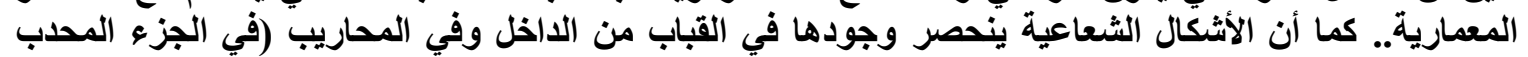

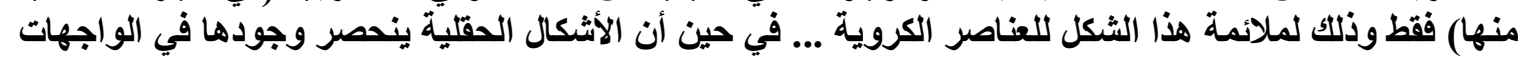

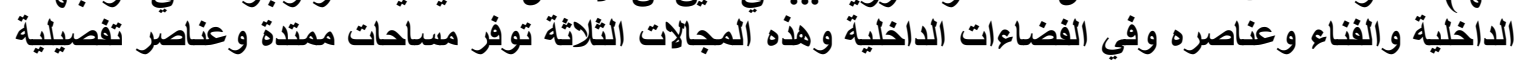

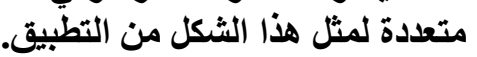

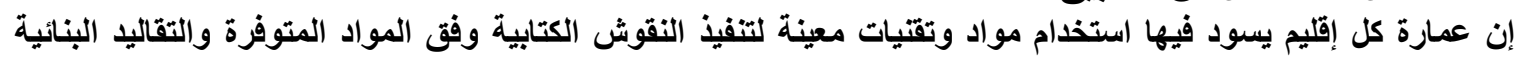

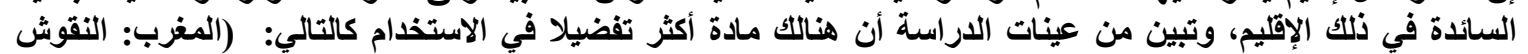

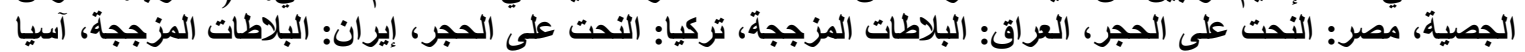

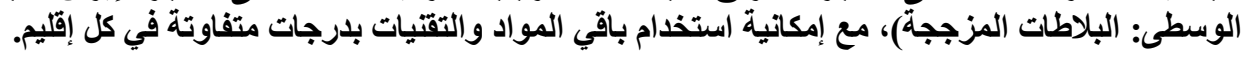

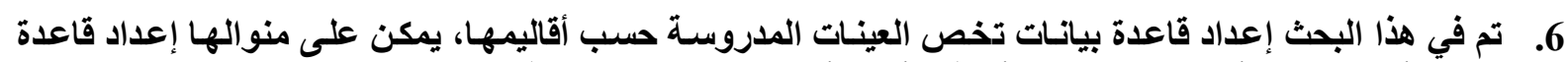

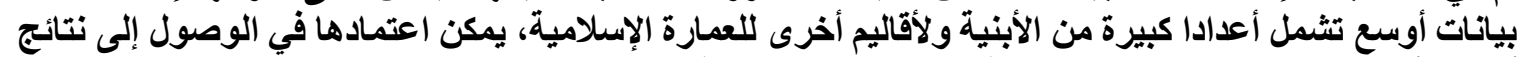

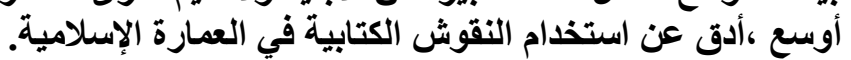

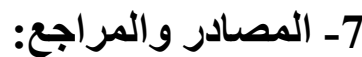

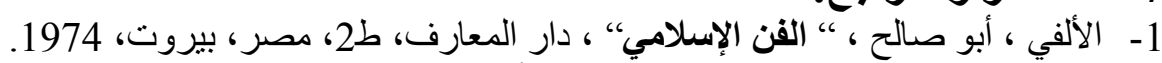

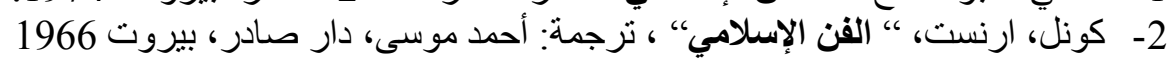

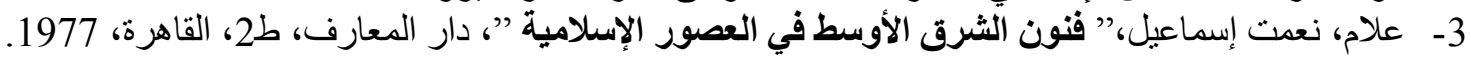

4- Holnd brand Hellenbrand, Robert," Islamic Art And Architecture ", Thames \& Hudson, London, 1999.

5- مصطفى، صالح لمعي، " التراث المعماري الإسلامي في مصر "، ط1، دار النهضة العربية للطباعة والنشر،

6يروت، 1984.

6- الاطرقجي، ثائر، " الأساسيات التصميمية للأشرطة الكتابية "، 2011، الموقع الالكتروني على الثبكة العنكبوتية .http://alatraqchi.blogspot.com/2011/02/blog-post.html

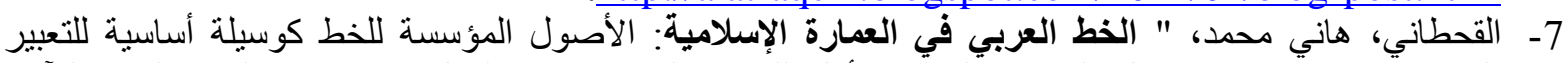

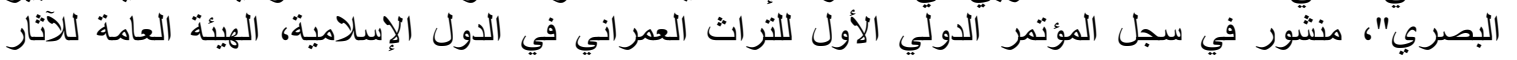
و التراث، الرياض، منشر في 2010.

8- Clevenot, Dominique , “ Ornament and decoration in Islamic architecture ", Thames \& Hudson, London, 2000.

9- الأعظمي، خالد خليل حمودي، " الزخارف الجدارية في آثار بغداد "، دار الرشبد، بغداد، 1980.

10- Michell, George and others," Architecture of The Islamic World", Thames and Hudson Ltd., London, 1978.

11- ثويني، علي، " معجم عمارة الشعوب الإسلامية" ، ط1، بيت الفيت الحكمة، بغداد،

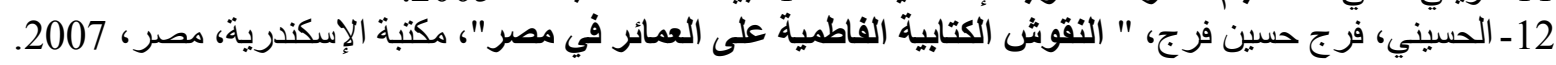


ذنون: الخصائص التصميمية للنقوش الكتابية في العمارة الإسلامية

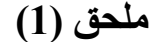

نموذج عينات النقوش الكتابية لمسجد ومدرسة وضريح السطان حسن / القاهرة

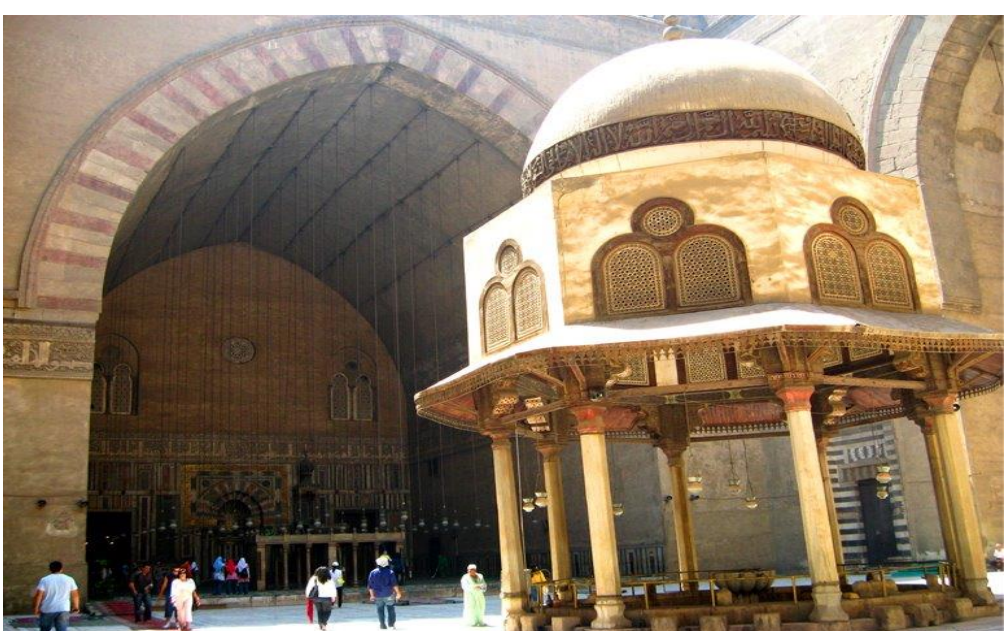

الكتابات على قبة الميضأة في الفناء و كتابات الإيوان

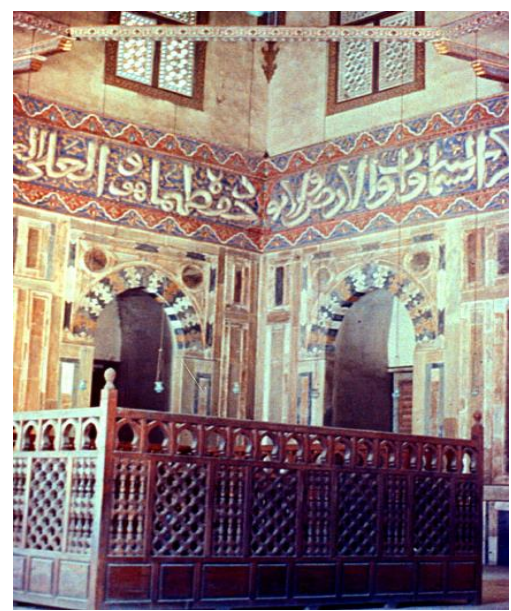

كتابات غرفة الضريح

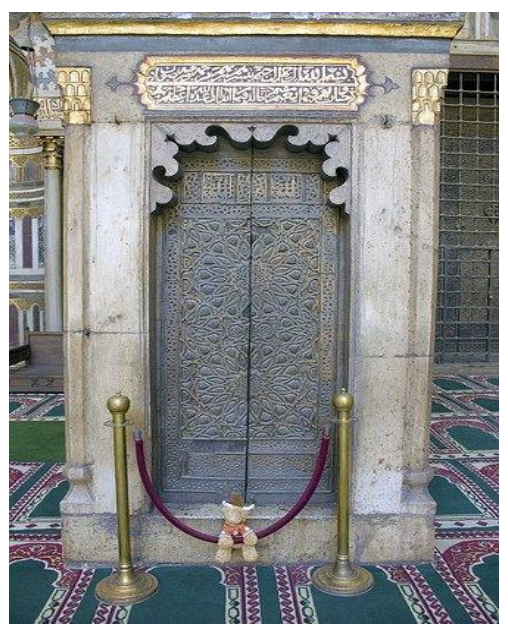

كتابات واجهة المنبر

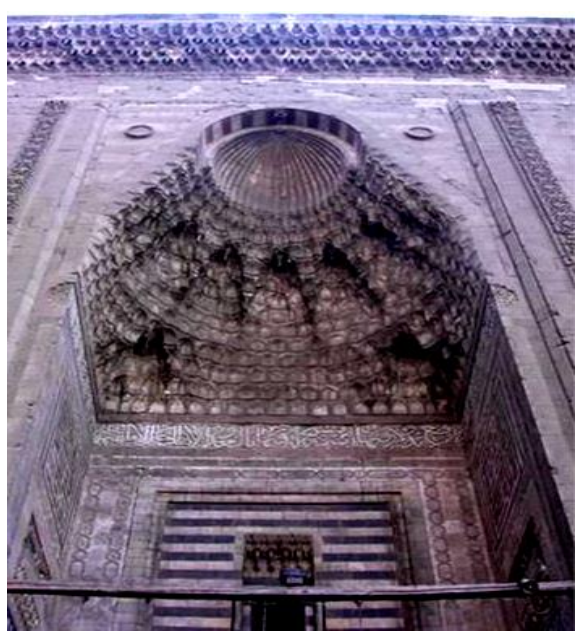

كتابات المدخل

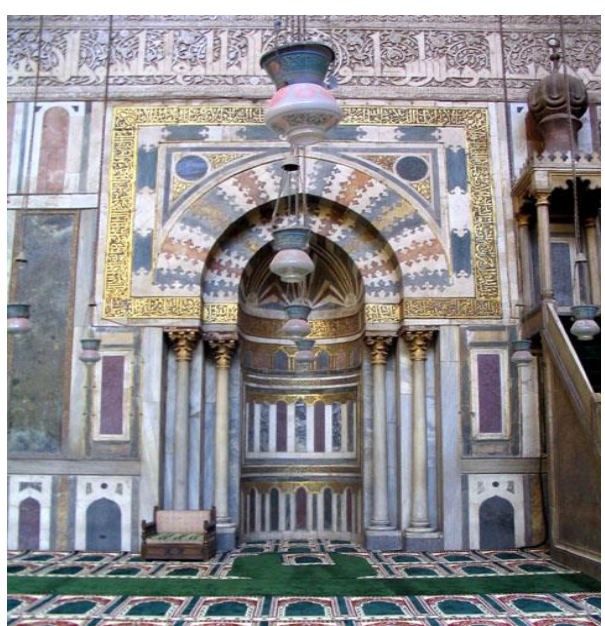

كتابات واجهة المحراب
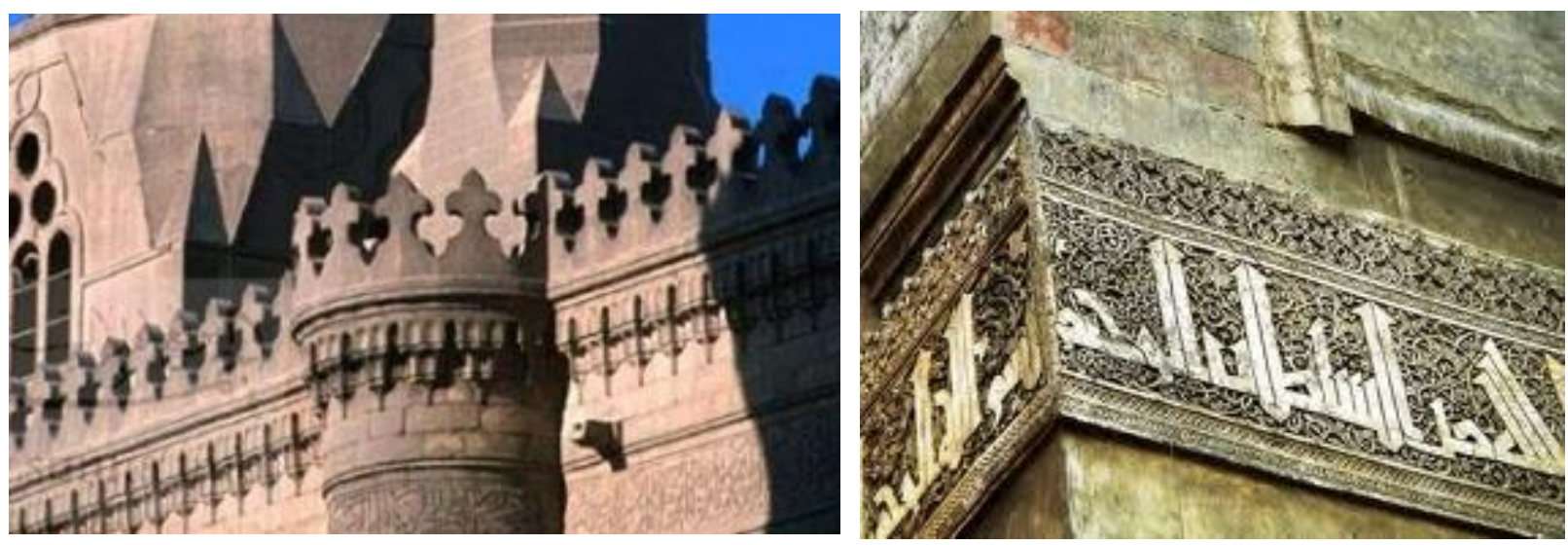

كتابات الواجهة الخارجية

تفصيل مكبر لكتابات الإيوان 